ARTICLE

\title{
In situ correlation between metastable phase- transformation mechanism and kinetics in a metallic glass
}

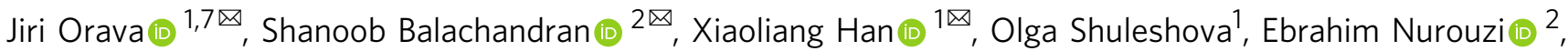 \\ Ivan Soldatov (1) ${ }^{3,4}$, Steffen Oswald ${ }^{1}$, Olof Gutowski ${ }^{5}$, Oleh Ivashko (1) ${ }^{5}$, Ann-Christin Dippel (1) ${ }^{5}$, \\ Martin v. Zimmermann (iD) ${ }^{5}$, Yurii P. Ivanov (10 ${ }^{6}$, A. Lindsay Greer (1) ${ }^{6}$, Dierk Raabe ${ }^{2}$, Michael Herbig ${ }^{2} \&$ \\ Ivan Kaban (1) ${ }^{1 凶}$
}

A combination of complementary high-energy X-ray diffraction, containerless solidification during electromagnetic levitation and transmission electron microscopy is used to map in situ the phase evolution in a prototype $\mathrm{Cu}-\mathrm{Zr}$-Al glass during flash-annealing imposed at a rate ranging from $10^{2}$ to $10^{3} \mathrm{~K} \mathrm{~s}^{-1}$ and during cooling from the liquid state. Such a combination of experimental techniques provides hitherto inaccessible insight into the phase-transformation mechanism and its kinetics with high temporal resolution over the entire temperature range of the existence of the supercooled liquid. On flash-annealing, most of the formed phases represent transient (metastable) states - they crystallographically conform to their equilibrium phases but the compositions, revealed by atom probe tomography, are different. It is only the $\mathrm{B} 2 \mathrm{CuZr}$ phase which is represented by its equilibrium composition, and its growth is facilitated by a kinetic mechanism of Al partitioning; Al-rich precipitates of less than $10 \mathrm{~nm}$ in a diameter are revealed. In this work, the kinetic and chemical conditions of the high propensity of the glass for the B2 phase formation are formulated, and the multi-technique approach can be applied to map phase transformations in other metallic-glass-forming systems.

\footnotetext{
${ }^{1}$ IFW Dresden, Institute for Complex Materials, Dresden, Germany. ${ }^{2}$ Max-Planck-Institut für Eisenforschung, Düsseldorf, Germany. ${ }^{3}$ IFW Dresden, Institute for Metallic Materials, Dresden, Germany. ${ }^{4}$ Institute of Natural Sciences, Ural Federal University, Ekaterinburg, Russia. ${ }^{5}$ Deutsches Elektronen-Synchrotron DESY, Hamburg, Germany. ${ }^{6}$ Department of Materials Science and Metallurgy, University of Cambridge, Cambridge, UK. ${ }^{7}$ Present address: Faculty of

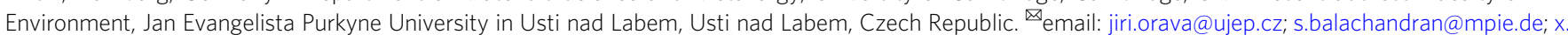
han@ifw-dresden.de; i.kaban@ifw-dresden.de
} 
$\mathrm{t}$ room temperature, applied strain on metallic glasses (MGs) results in inhomogeneous plastic flow initially localized into $\sim 10-20 \mathrm{~nm}$ thick shear bands ${ }^{1}$. Yielding of MGs, with a universal shear strain of $2.67 \pm 0.02 \%^{2}$, is accompanied by significant softening, resulting in a catastrophic failure. By controlling and tuning intrinsic heterogeneities in $\mathrm{MGs}^{3}$ via external stimuli, such as non-affine thermal ${ }^{4}$ and elastic ${ }^{5}$ strains, significant improvement in MGs' formability is achieved-compressive plastic strain can increase up to $\sim 6 \%{ }^{4}$, and MGs can show strain-hardening ${ }^{6}$.

Plasticity can be enhanced by introducing a deformable crystalline phase(s) into the glass ${ }^{7,8}$. For such composites, the mechanical properties can be controlled by tuning the type and size of the crystals formed. For example, in pure nanocrystalline $\mathrm{Cu}$, a bimodal crystal size distribution might be beneficial, with nanometer-sized grains providing strength, combined with micrometer-sized grains giving strain-hardening 9 . The composite formation is better controlled on heating MGs, giving access to a wide range of heating rates $(\Phi)$ of about 8 orders of magnitude, rather than on cooling the liquid.

In the archetype equimolar $\mathrm{CuZr}$ and derived CuZr-based MGs, the presence of the $\mathrm{B} 2 \mathrm{CuZr}$ phase (space group $\mathrm{Pm} \overline{3} \mathrm{~m}$ ) is beneficial for enhancing plastic compliance of metallic-glass-crystal composites ${ }^{10}$. Some Cu-rich phases give hardness to composites, and they can also provide additional functionalities such as antibacterial properties ${ }^{11}$, though such crystals are brittle and prone to corrosion. The B2 phase is stable at $T>900 \mathrm{~K}$, but it can already form on isothermal annealing at $671 \mathrm{~K}$, or during primary crystallization on conventional heating at $\Phi \leq 60 \mathrm{~K} \mathrm{~min}^{-1}$ where the crystallization onset temperature, $T_{\mathrm{x}}$, lies below the $\mathrm{B} 2$ forming temperature in the binary system ${ }^{12-14}$. The volume fraction of the B2 phase formed at such conditions is low and B2 decomposes into the equilibrium phases below $900 \mathrm{~K}^{13}$.

The B2 phase has been shown to form on fast heating, it can form on a millisecond timescale, translating to $\Phi$ in the range of $\sim 10^{2} \mathrm{~K} \mathrm{~s}^{-1}$. Flash-annealing suppresses the formation of the lowtemperature thermodynamic equilibrium phases $\mathrm{Cu}_{10} \mathrm{Zr}_{7}$ (space group C2ca) and $\mathrm{CuZr}_{2}$ (space group $\mathrm{I} 4 / \mathrm{mmm}$ ), and gives the possibility to control the $\mathrm{B} 2$ phase content. For the $\mathrm{Cu}_{47.5} \mathrm{Z}$ $\mathrm{r}_{47.5} \mathrm{Al}_{5.0} \mathrm{MG}$ studied here, $\Phi$ as high as $\sim 700 \mathrm{~K} \mathrm{~s}^{-1}$ was suggested to be needed, though $\mathrm{Cu}_{10} \mathrm{Zr}_{7}$ could not be fully suppressed ${ }^{15}$. Composites formed by flash-annealing with $\Phi>100 \mathrm{~K} \mathrm{~s}^{-1}$ during resistive (Joule) ${ }^{15}$ and inductive heating ${ }^{16}$ dominated by the metastable B2 phase can achieve a compressive strain of about $10 \%$ (crystals: $\sim 10 \mu \mathrm{m}$ in diameter and $\sim 15$ vol. $\%$ of B2) for $\mathrm{Cu}-$ Zr-based bulk MGs ${ }^{16}$. Flash-annealing may introduce crystals as small as $\sim 1.5-2 \mathrm{~nm}$, which is close to the theoretical limit of the critical nucleus, that can promote crystallization in MGs upon deformation, thereby also improving plasticity when an optimum grain-size range is reached ${ }^{17,18}$. So far, flash-annealing techniques ${ }^{15,16,19-24}$ and ultra-fast differential scanning calorimetry (FDSC) ${ }^{25-27}$, or a combination of both ${ }^{24}$, have been predominantly used to study the kinetics of the glass-transition temperature, $T_{\mathrm{g}}$, and $T_{\mathrm{x}}$ at $\Phi$ up to $\sim 10^{6} \mathrm{~K} \mathrm{~s}^{-1}$ in $\mathrm{Cu}-\mathrm{Zr}$-based MGs. Yet, the crystallization mechanism underlying the observed kinetics could only be accessed ex situ, based on the microstructure and XRD phase analysis, and the existing phasetransformation diagrams have been mostly derived by plotting the projection of CuZr equilibria. The $\Phi$ range for in situ X-ray experimental studies of crystallization in $\mathrm{Cu}_{50} \mathrm{Zr}_{50} \mathrm{MG}$, for which details of the mechanism were suggested ${ }^{12-14}$, has been limited to conventional $\Phi \leq 60 \mathrm{~K} \mathrm{~min}^{-1}$, which is $2-3$ orders of magnitude lower than the $\Phi$ required for composite formation. Küchemann and Samwer carried out an in situ X-ray diffraction study of the crystallization sequence during flash-annealing of $\mathrm{Zr}_{64.0} \mathrm{Cu}_{28.2} \mathrm{Al}_{7.8}$ MG ribbons ${ }^{19}$. However, due to the capacitor-discharge heating,
$\Phi$ remained limited to high heating rates of $\sim 10^{6} \mathrm{~K} \mathrm{~s}^{-1}$, and the crystallization was dominated by $\mathrm{ZrO}_{2}$ formation ${ }^{19}$.

The competition between the formation of the phases needs to be clearly understood to create composites with on-demand and often multifaceted properties, such as has been widely applied to make composites with low-energy-loss soft-magnetic properties $^{29}$. Hitherto, tracking and understanding in situ the phase evolution underlying the fast kinetics was impossible because $\Phi$ was not in a region relevant for composite formation, limited by conventional experimental techniques. Therefore, crystallization mechanisms could be deduced from ex situ examinations only, for which, as will be shown later, unwanted phase transformation on cooling may occur. Also, crystallization mechanisms of ternary alloys have been extrapolated from binary systems, especially from $\mathrm{Cu}_{50} \mathrm{Zr}_{50}$ glass, which is a too simplified approach.

In this work, a combination of in situ high-energy X-ray diffraction with a high temporal resolution is carried out during resistive flash-annealing and during containerless solidification via electromagnetic levitation (EML), and those are complemented by in situ transmission electron microscopy (TEM). The crystallization mechanism of the low- and high-temperature phases (represented by $\mathrm{Cu}_{10} \mathrm{Zr}_{7}, \mathrm{CuZr}_{2}$ and $\mathrm{B} 2$ phase, respectively) and kinetics can be correlated in $\mathrm{Cu}_{47.5} \mathrm{Zr}_{47.5} \mathrm{Al}_{5.0}$ glassy ribbons on $\sim 4 \mathrm{~ms}$ timescale. Controlled cooling in a chamber flushed with helium is demonstrated to maximize the $\mathrm{B} 2$ content in the composite. The local microstructure is analyzed by atom probe tomography (APT) and TEM; the presence of nanometerlength-scale Al-rich precipitates within and around the B2 phase is resolved.

\section{Results}

The kinetic conditions of phase transformation. A critical $\Phi$ to form a composite with a predominant fraction of the $\mathrm{B} 2 \mathrm{CuZr}$ phase in $\mathrm{Cu}_{47.5} \mathrm{Zr}_{47.5} \mathrm{Al}_{5.0}$ was suggested to be $\sim 700 \mathrm{~K} \mathrm{~s}^{-1} .15$ Two flash-annealing examples are presented in detail by in situ XRD: one case shows a subcritical $\Phi$ in the range $100-150 \mathrm{~K} \mathrm{~s}^{-1}$ (Fig. 1), and the other a supercritical $\Phi$ of about $1100 \mathrm{~K} \mathrm{~s}^{-1}$ (Fig. 2) in a vacuum. The full $\Phi$-dependence is discussed later in the "Mapping the correlation between kinetics and crystallization mechanism" section. For low $\Phi$, the resistive heating is non-linear (Fig. 1a-red curve). All the $\Phi$ values given here are estimated by assuming linear heating from room temperature to $T_{\mathrm{x}}$, and are comparable with flash-annealing ${ }^{15,30}$ and FDSC $^{28}$. It must be noted that according to APT results, the local stoichiometry was reached for the B2 phase only, independent of heating/cooling conditions as detailed in the latter sections. For simplicity, the stoichiometric compound nomenclature is kept throughout the manuscript.

On subcritical heating at $100-150 \mathrm{~K} \mathrm{~s}^{-1}, T_{\mathrm{x}}$ is $831 \mathrm{~K}$ represented by the sharp drop in the resistance at $t_{\mathrm{x}}=3532 \mathrm{~ms}$ and the temperature rise on the $T(t)$-curve due to recalescence (Fig. 1a). A 3-D representation of the temporal evolution of XRD patterns is given in Supplementary Fig. 1. The following phase identification, and all others discussed in the upcoming sections, is rationalized by Rietveld refinement. For the subcritical $\Phi$, the best-fit refinement is shown in Supplementary Fig. 2. The identified phases at specific stages of heating and cooling are shown in Fig. 1c (only the most pronounced peaks are marked by the corresponding symbols). The crystallization proceeds via the formation of the equilibrium low-temperature $\mathrm{Cu}_{10} \mathrm{Zr}_{7}$ phase preceding the $\mathrm{B} 2$ phase formation by $\sim 56 \mathrm{~ms}$ (Fig. $1 \mathrm{~b}, \mathrm{c}$ ). By analyzing 20 summed intensities taken around point 4 in Fig. 1a, $t=3628-3704 \mathrm{~ms}$ and $T \approx 1007-1013 \mathrm{~K}$, the Rietveld refinement confirmed the presence of the two main phases (Supplementary 

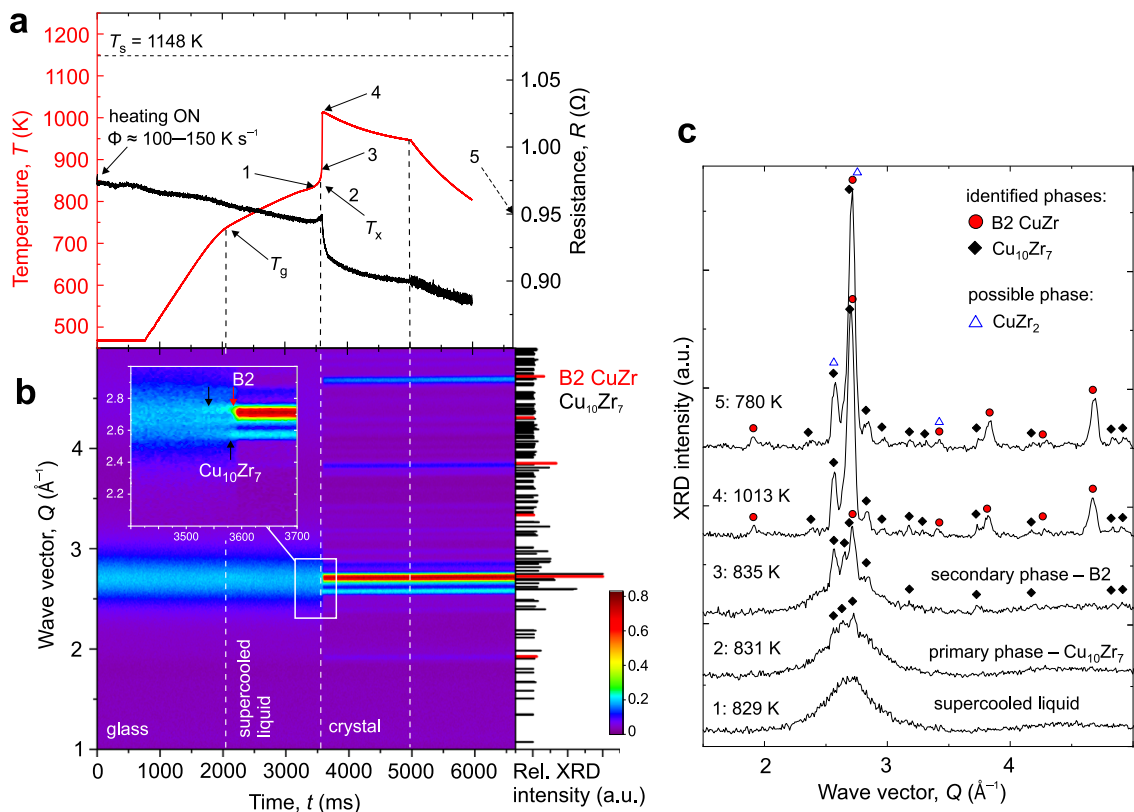

Fig. 1 In situ high-energy $X$-ray diffraction revealing the crystallization mechanism on flash-annealing at a subcritical heating rate of $\mathbf{C u}_{47.5} \mathbf{Z r}_{47.5} \mathrm{Al}_{5.0}$ ribbon in a vacuum. a Time-dependent temperature (red) and resistance (black) on flash-annealing at $\Phi \approx 100-150 \mathrm{~K} \mathrm{~s}^{-1}$. b The temporal evolution of high-energy $\mathrm{X}$-ray pattern. The inset shows a close-up of the crystallization onset for $\mathrm{Cu}_{10} \mathrm{Zr}_{7}$ (black arrows) and B2 CuZr (red arrows) phases. The righthand part in part $\mathbf{b}$ plots the relative $X$-ray intensities which are normalized to the highest-intensity peak. c Selected individual XRD patterns showing the different stages of crystallization and phase transformations. Full and open symbols label respectively the position of the most pronounced peaks of the identified and possible phases revealed by Rietveld refinement-details can be found in Supplementary Information, Supplementary Fig. 2 (high-energy XRD) and Supplementary Fig. 3 (laboratory XRD). The labeled points correspond to the time of 1: $3505 \mathrm{~ms} ; 2: 3532 \mathrm{~ms} ; 3: 3588 \mathrm{~ms} ; 4: 3610 \mathrm{~ms}$; and 5: $6645 \mathrm{~ms}$. Source data of the XRD patterns are provided on https://archive.materialscloud.org/61.
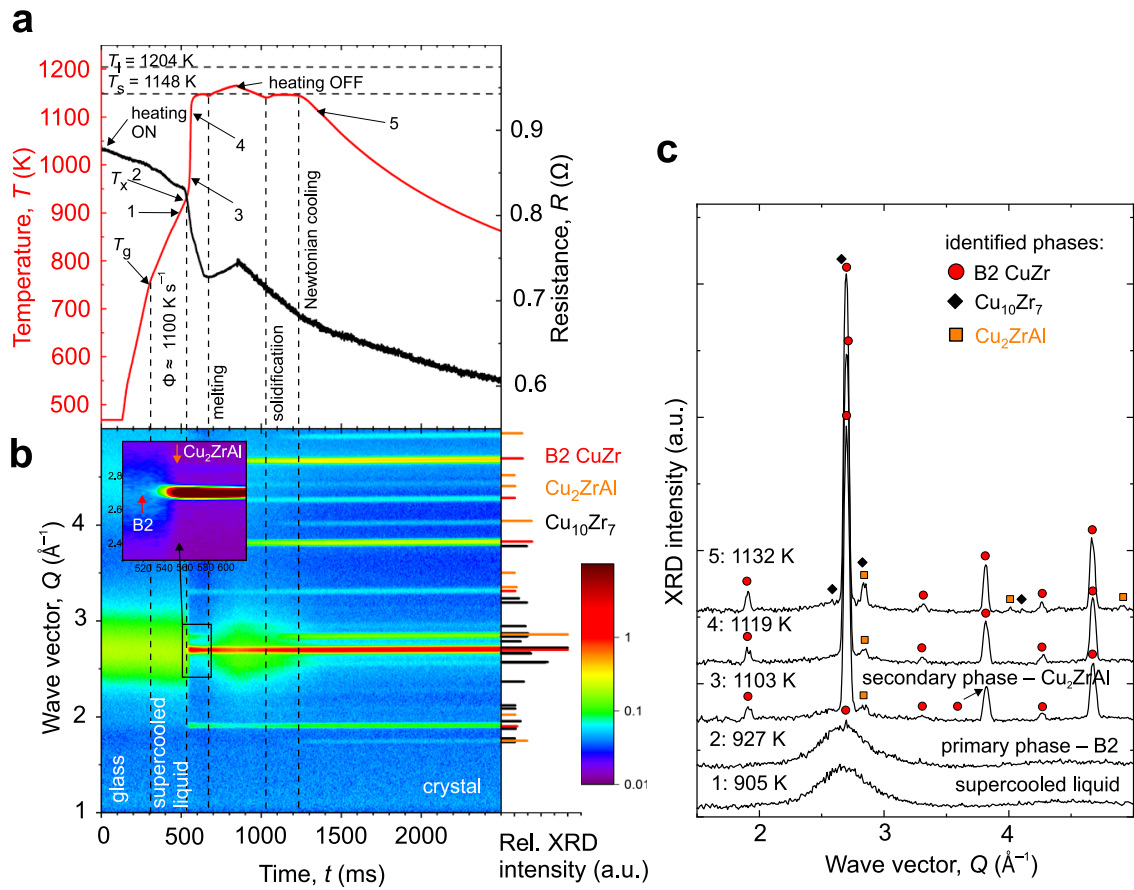

Fig. 2 In situ high-energy X-ray diffraction revealing the crystallization mechanism on flash-annealing at a supercritical-heating rate of the glass in a vacuum. a Time-dependent temperature (red) and resistance (black) of $\mathrm{Cu}_{47.5} \mathrm{Zr}_{47.5} \mathrm{Al}_{5.0}$ glassy ribbon when resistively heated at a heating rate of $\Phi \approx$ $1100 \mathrm{~K} \mathrm{~s}^{-1}$ and cooled in a vacuum. $\mathbf{b}$ The corresponding temporal evolution of high-energy $\mathrm{X}$-ray patterns on heating and cooling. The inset, in part $\mathbf{b}$, shows a close-up of the crystallization onset for B2 (red arrow) and $\mathrm{Cu}_{2} \mathrm{ZrAl}$ (orange arrow) phases. Right-hand part in part $\mathbf{b}$ : The relative $\mathrm{X}$-ray intensities are normalized to the highest-intensity peak. For clarity, only selected $\mathrm{Cu}_{10} \mathrm{Zr}_{7}$ diffraction peaks are plotted (see Fig. 1, part $\mathbf{b}$, for the complete plot). c Selected individual XRD patterns showing the different stages of crystallization and phase transformations. Full symbols label the position of the most pronounced peaks of the identified phases revealed by Rietveld refinement-details can be found in Supplementary Information, Supplementary Fig. 4 (heating), and Supplementary Fig. 6 (cooling). The labeled points correspond to the time of 1: $489 \mathrm{~ms} ; 2: 520 \mathrm{~ms} ; 3: 552 \mathrm{~ms} ; 4: 566 \mathrm{~ms}$; and 5: $1300 \mathrm{~ms}$. Source data of the XRD patterns are provided on https://archive.materialscloud.org/ 61 . 
Fig. 2a). The low-temperature $\mathrm{CuZr}_{2}$ phase, reported in the literature to form parallel to and/or just after $\mathrm{Cu}_{10} \mathrm{Zr}_{7}$ during the primary crystallization ${ }^{12-14}$, could not be unambiguously identified in the individual high-energy XRD patterns on heating. This is because of $\mathrm{CuZr}$ 2 possible low quantity and the low associated XRD intensity, and because the XRD patterns are predominated by $\mathrm{Cu}_{10} \mathrm{Zr}_{7}$ in the $Q$-range of interest for $\mathrm{CuZr}_{2}$. The Rietveld refinement, Supplementary Fig. $2 b$, hints at the possible presence of $\mathrm{CuZr}_{2}$ phase around point 4 in Fig. 1a, but considering high uncertainty of the fitting this just gives an indicative trend, and the exact $T$ and $t$ for the CuZr $r_{2}$ formation on heating and cooling could not be resolved in situ. The possible presence of $\mathrm{CuZr}_{2}$ could also be hinted by analyzing laboratory XRD measurements of the final microstructure at room temperature (see Rietveld refinement shown in Supplementary Fig. 3); yet, if anything, the phase fraction must be quite low. When the electrical current ceases at $t=5000 \mathrm{~ms}$, the initial cooling rate is $\sim 300 \mathrm{~K} \mathrm{~s}^{-1}$ in a vacuum of $10^{-4}$ mbar. Due to the low X-ray intensity, there was macroscopically no detectable $\mathrm{Cu}_{10} \mathrm{Zr}_{7}$ coarsening via $\mathrm{B} 2$ decomposition as would be expected from the eutectoid reaction of $13 \mathrm{CuZr} \rightarrow \mathrm{Cu}_{10} \mathrm{Zr}_{7}+3 \mathrm{CuZr}_{2}$ on cooling $\mathrm{Cu}_{50} \mathrm{Zr}_{50}{ }^{25}$; where $T_{\mathrm{e}}=975 \mathrm{~K}$ for the studied glass ${ }^{28}$.

On supercritical heating at $\sim 1100 \mathrm{~K} \mathrm{~s}^{-1}$ (Fig. 2), the $\mathrm{Cu}_{10} \mathrm{Zr}_{7}$ crystallization was suppressed, and B2 became the primary phase at $T_{\mathrm{x}} \approx 927 \mathrm{~K}$. Because of the higher temperature reached and the suppressed $\mathrm{Cu}_{10} \mathrm{Zr}_{7}$ formation, the high-temperature $\mathrm{Cu}_{2} \mathrm{ZrAl}$ phase $\left(\tau_{4}\right.$, space group $\left.\mathrm{Fm} \overline{3} \mathrm{~m}\right)$ formed as the secondary phase at $T \approx 1103 \mathrm{~K}$ delayed by $\sim 32 \mathrm{~ms}$ (Fig. $2 \mathrm{~b}, \mathrm{c}$ ). The presence of the two main phases on heating was confirmed by Rietveld analysis (Supplementary Fig. 4) of 10 summed intensities around point 4 in Fig. 2a, i.e., between $t=552-589 \mathrm{~ms}$ corresponding to $T \approx$ $1103-1145 \mathrm{~K}$. It is worth noting that this point is about $\sim 150 \mathrm{~K}$ higher than the point 4 shown in Fig. 1a. The ternary phase typically forms on isothermal annealing at temperatures of 1000 $-1100 \mathrm{~K}^{11,31}$, or at $T_{\mathrm{x}}=861 \mathrm{~K}$ on heating $\mathrm{Cu}_{46} \mathrm{Zr}_{46} \mathrm{Al}_{8}$ glass at $20 \mathrm{~K} \mathrm{~min}^{-132}$. The formation of $\mathrm{Cu}_{2} \mathrm{ZrAl}$ during heating was not considered in a FDSC study of $\mathrm{Cu}_{47.5} \mathrm{Zr}_{47.5} \mathrm{Al}_{5.0}$ glass as calorimetry does not provide any information required for phase identification $^{28}$. Yet, a DSC trace of heating at $\Phi=1000 \mathrm{~K} \mathrm{~s}^{-1}$ (see Fig. 2a in ref. ${ }^{28}$ ) shows a possible two-step crystallization and, by deconvoluting the peak into two gives a second onset temperature for phase formation of $\sim 950 \mathrm{~K}$-this is close to that of $\sim 927 \mathrm{~K}$ at $\Phi \approx 1100 \mathrm{~K} \mathrm{~s}^{-1}$ in the present work. The values of $T_{\mathrm{g}} \approx 750 \mathrm{~K}, T_{\mathrm{x}}=831 \mathrm{~K}$ at $100-150 \mathrm{~K} \mathrm{~s}^{-1}$ and $T_{\mathrm{g}} \approx 775 \mathrm{~K}, T_{\mathrm{x}}=$ $927 \mathrm{~K}$ at $\sim 1100 \mathrm{~K} \mathrm{~s}^{-1}$ are in good agreement with those obtained by $\operatorname{FDSC}^{28}$. This trend also indicates that the linear $\Phi$ approximation for flash-annealing gives a reasonable value for an effective $\Phi$. The fast-heated ribbon could be partially melted while maintaining its shape. When the solidus temperature $T_{\mathrm{s}}=$ $1148 \mathrm{~K}$ was reached, the $\mathrm{Cu}_{2} \mathrm{ZrAl}$ and the $\mathrm{B} 2$ phases started to melt; on prolonged annealing, the $\mathrm{Cu}_{2} \mathrm{ZrAl}$ phase melted completely (Fig. 2b, and Supplementary Fig. 3 showing a 3-D representation of the crystallization, re-melting, and the onset of Newtonian cooling). On ceasing the current at $t=845 \mathrm{~ms}$, a cooling rate of $\sim 140 \mathrm{~K} \mathrm{~s}^{-1}$ and a small effective supercooling of $\Delta T \approx 66 \mathrm{~K}\left(=T_{1}-T ; T_{1}\right.$-liquidus temperature) were achieved before the solidification of $\mathrm{Cu}_{2} \mathrm{ZrAl}$ and re-growth of the $\mathrm{B} 2$ phase, giving the recalescence at $t=1139 \mathrm{~ms}$, took place. With further cooling, $\mathrm{Cu}_{10} \mathrm{Zr}_{7}$ phase formed from the supercooled liquid at $T=1132 \mathrm{~K}$ and $t=1300 \mathrm{~ms}$ (Fig. 2c), and this phase formation is generally difficult to suppress (Supplementary Fig. 6). Later, in the TEM and the microstructure-analysis paragraphs, we will show that $\mathrm{Cu}_{10} \mathrm{Zr}_{7}$ coarsens upon cooling in a vacuum; this is also an effect observed for $\mathrm{Cu}-\mathrm{Zr}$-based cast glasses ${ }^{33}$. In Fig. 2, the B2 continuous growth was observed on cooling down to $\sim 1100 \mathrm{~K}$. For the supercritical-heating conditions, the $\mathrm{CuZr}_{2}$ phase could not be identified by the phase analysis neither during heating nor during cooling stages (Supplementary Figs. 4 and 6). As in Fig. 1, the similarity in the Bragg reflections makes the $\mathrm{CuZr}_{2}$ quantification by XRD difficult, since no distinct peaks were observed we conclude that its fraction must be much lower than for slower $\Phi$ shown in Fig. 1. The $\mathrm{CuZr}_{2}$ phase will be resolved later by EML.

The above results suggest that there is the formation of the brittle low-temperature phases, predominantly $\mathrm{Cu}_{10} \mathrm{Zr}_{7}$ and possibly minor $\mathrm{CuZr}_{2}$, on cooling in vacuum. To suppress this undesirable formation and to better control the $\mathrm{B} 2$ phase fraction, a chamber flushed with He giving cooling rates $1000-2000 \mathrm{~K} \mathrm{~s}^{-1}$, one order of magnitude higher than in a vacuum, was used. In Fig. 3, about two times larger electric power was applied to compensate for the efficient cooling to achieve $\Phi$ comparable with flash-annealing in a vacuum. The highest temperature reached was $1023 \mathrm{~K}$ (Fig. 3a), $\sim 50 \mathrm{~K}$ above $T_{\mathrm{e}}$. The primary crystallization was dominated by the $\mathrm{B} 2$ phase formation at $T_{\mathrm{x}} \approx$ $885 \mathrm{~K}, t_{\mathrm{x}}=545 \mathrm{~ms}$ (Fig. $3 \mathrm{c}$ ). Defining one average $\Phi$, unlike in vacuum, is rather too simplified in the case of He atmosphere. When the glass enters its supercooled liquid region, the efficient He cooling results in effectively much slower $\Phi$ (see the slowing down in the effective $\Phi$ in Fig. 3a). This provided some time for the appearance of the sluggish $\mathrm{Cu}_{10} \mathrm{Zr}_{7}$ phase, yet its fraction was extremely low, and it could only be detected at later stages of heating, when a larger volume fraction had formed (see Supplementary Fig. 7 showing Rietveld analysis at point 4 of the heating part in Fig. 3a; 20 individual XRD patters were summed between $t=609-686 \mathrm{~ms}$ corresponding to $T \approx$ 978-1024 K). There was no evidence for the presence of $\mathrm{CuZr}_{2}$ and $\mathrm{Cu}_{2} \mathrm{ZrAl}$ phases in the XRD pattern by the Rietveld refinement. On cooling, unlike in Fig. 2, there was no detectable $\mathrm{Cu}_{10} \mathrm{Zr}_{7}$ coarsening (see also Supplementary Fig. 8 for a 3-D representation).

In order to understand the details of the solidification of $\mathrm{Cu}_{47.5} \mathrm{Zr}_{47.5} \mathrm{Al}_{5.0}$ supercooled liquid and the competition in phase formation on cooling, containerless processing ${ }^{34}$ via EML (Fig. 4) was used to complement the flash-annealing. The XRD instability seen in Fig. $4 \mathrm{~b}$ during heating up to $T_{\mathrm{s}}$ was caused by sample oscillations (shape instabilities) whilst levitating the solid-state alloy inside a $\mathrm{Cu}$-coil, and extra peaks belonging to the $\mathrm{Al}_{2} \mathrm{O}_{3}$ sample support were detected. Heating was used to determine $T_{1}$ for pyrometer calibration only. The liquid supercooling $\Delta T$ was calculated from the lowest $T$-point read by the pyrometer before a steep temperature rise occurred due to the recalescence. Along the lines of thoughts for flash-annealing, Rietveld analysis of the XRD intensity, taken at point 4 in Fig. $4 \mathrm{a}, t=50.2 \mathrm{~s}$ and $T=1134 \mathrm{~K}$, was carried out. The presence of all phases being relevant in this study, i.e., $\mathrm{B} 2 \mathrm{CuZr}, \mathrm{Cu}_{10} \mathrm{Zr}_{7}, \mathrm{CuZr}_{2}$, and $\mathrm{Cu}_{2} \mathrm{ZrAl}$ can be seen in Supplementary Fig. 9. On cooling, the B2 always nucleated as the primary phase-the kinetics is evaluated in the next section. In the experiment presented in Fig. 4, B2 phase formed at an apparent nucleation temperature of $T_{\mathrm{n}}=972 \mathrm{~K}(\Delta T=232 \mathrm{~K})$, followed by $\mathrm{Cu}_{2} \mathrm{ZrAl}$ and $\mathrm{CuZr}_{2}$ phases both forming at $T \sim$ $987 \mathrm{~K}$ and delayed by $0.4 \mathrm{~s}$ relative to the appearance of $\mathrm{B} 2$; where the delay time $\Delta t=t_{\mathrm{x}}-t_{1} ; t_{1}=0 \mathrm{~s}$ when $T_{1}$ is passed on cooling. For some supercooling conditions, weak Bragg reflections of the B2 phase were identified before the recalescence event resolved by pyrometer, a possible consequence of the stochastic nature of the nucleation. Although the $\mathrm{CuZr}_{2}$ phase could not be unambiguously identified in flash-annealing, the complementary data by EML readily evidence this phase, and that the overall phasetransformation mechanism conforms to the flash-annealing results. The $\mathrm{Cu}_{10} \mathrm{Zr}_{7}$ phase possibly nucleated during the recalescence, but it could only be identified on XRD intensity 

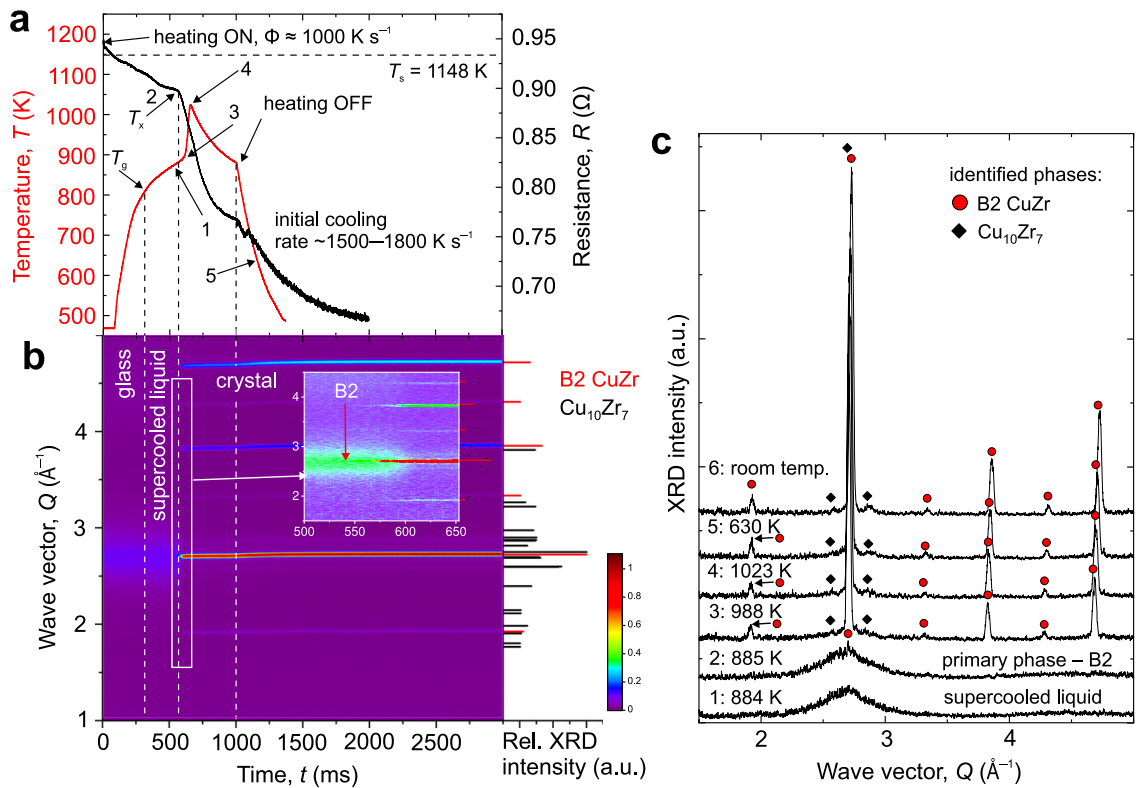

Fig. 3 In situ X-ray diffraction revealing crystallization mechanism on flash-annealing in a chamber fluxed with He. a Time-dependent temperature (red) and resistance (black) of $\mathrm{Cu}_{47.5} \mathrm{Zr}_{47.5} \mathrm{Al}_{5.0}$ ribbon when resistively heated at a heating rate of $\Phi \approx 1000 \mathrm{~K} \mathrm{~s}^{-1}$ while being fluxed with He. b The corresponding temporal evolution of the high-energy X-ray pattern. The inset shows a close-up of the crystallization onset for B2 phase (red arrow). Righthand part: The relative $\mathrm{X}$-ray intensities are normalized to the highest-intensity peak. For better clarity, only selected $\mathrm{Cu}_{10} \mathrm{Zr}_{7}$ diffraction peaks are plotted. c Selected individual XRD patterns showing the different stages of crystallization and phase transformations. Full symbols label the position of the most pronounced peaks of the identified phases revealed by Rietveld refinement-details can be found in Supplementary Information, Supplementary Fig. 7. The labeled points correspond to the time of 1: $541 \mathrm{~ms} ; 2: 545 \mathrm{~ms} ; 3: 606 \mathrm{~ms} ; 4: 657 \mathrm{~ms} ; 5: 1165 \mathrm{~ms}$, and 6: 7468 ms (room temperature). Source data of the XRD patterns are provided on https://archive.materialscloud.org/61.
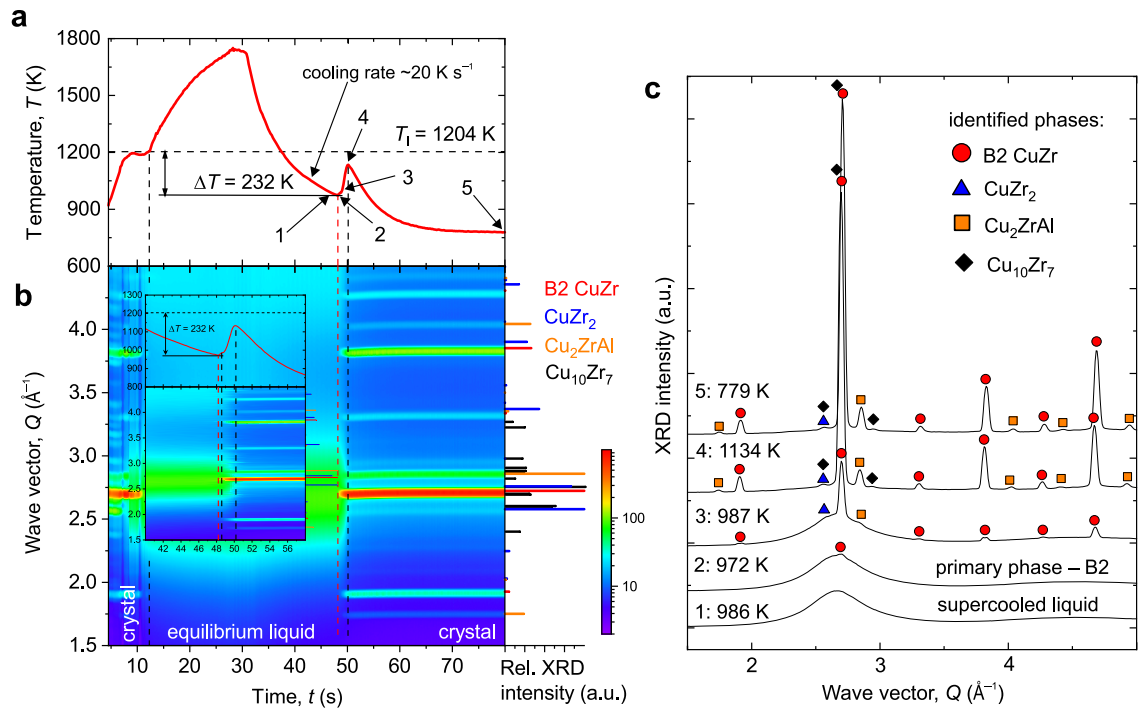

Fig. 4 In situ high-energy X-ray diffraction showing phase-formation sequence during solidification of supercooled $\mathrm{Cu}_{47.5} \mathrm{Zr}_{47.5} \mathrm{Al}_{5.0}$ liquid in EML facility. a Temperature profile showing the achieved supercooling of $\Delta T=232 \mathrm{~K}=\left(T_{1}-T\right) ; T_{1}$ is the liquidus temperature. A typical cooling rate before the recalescence is $\sim 20 \mathrm{~K} \mathrm{~s}^{-1}$. $\mathbf{b}$ The corresponding evolution of $X$-ray pattern measured at $5 \mathrm{~Hz}$. The inset shows a close-up of the solidification process. Righthand part: The relative XRD intensities of selected peaks normalized to the highest-intensity peak are depicted. c Selected individual XRD patterns showing the different stages of solidification on cooling. Full symbols label the position of the most pronounced peaks of the identified phases revealed by Rietveld refinement-details can be found in Supplementary Information, Supplementary Fig. 9. The labeled points correspond to the time of 1: $47 \mathrm{~s} ; 2: 48.2 \mathrm{~s} ; 3$ : 48.6 s; 4: 50.2 s; and 5: 80 s. Source data of the XRD patterns are provided on https://archive.materialscloud.org/ ${ }^{61}$.

beginning from point 4, shown in Fig. 4a, c, when enough volume fraction had formed.

Complementing the in situ XRD studies above, heating inside TEM was used to understand local conditions under which the individual phases form on heating and on cooling (Fig. 5). Local amorphicity in the as-spun ribbon, without indications of clustering and phase separation, was confirmed by HRTEM and SAED (Supplementary Fig. 10). The composition by EDX was $\mathrm{Cu}_{48} \mathrm{Zr}_{47} \mathrm{Al}_{5}$ ( \pm 1 at.\%). A top oxide layer, $\sim 5 \mathrm{~nm}$ thick, had no observable influence on the annealing experiments. No thermal drift was observed ${ }^{35}$. Heating of a thin foil at $\Phi \approx 220 \mathrm{~K} \mathrm{~s}^{-1}$, a $\Phi$-range dominated by $\mathrm{Cu}_{10} \mathrm{Zr}_{7}$ formation, revealed a distinct 

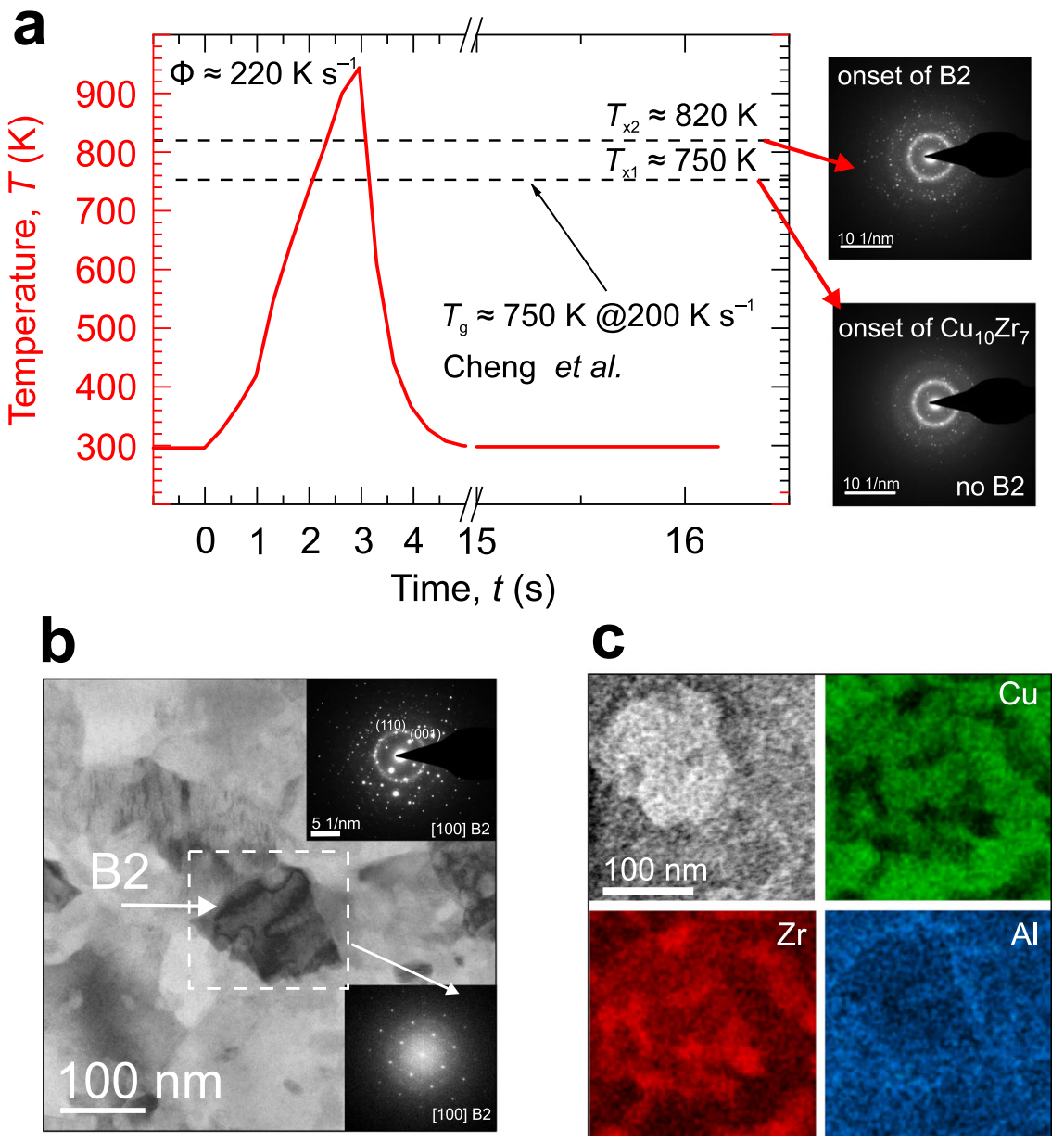

$\mathrm{Zr}$

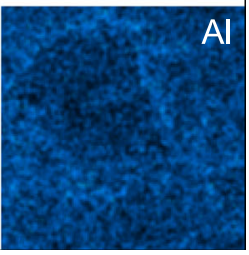

Fig. 5 In situ TEM showing the crystallization mechanism and the final microstructure formed in a confined environment at a subcritical heating rate of about $220 \mathbf{~ s ~ s}^{-1}$ in a vacuum. a Heating profile of a glassy $\mathrm{Cu}_{47.5} \mathrm{Zr}_{47.5} \mathrm{Al}_{5.0}$ thin foil. Two crystallization temperatures $T_{x 1}$ and $T_{x 2}$ corresponding respectively to the onset of $\mathrm{Cu}_{10} \mathrm{Zr}_{7}$ and $\mathrm{B} 2$ phase formation-represented on the right-hand by SAED patterns-can be identified. The value of the glasstransition temperature, $T_{\mathrm{g}}$ of a ribbon sample is taken from Cheng et al. ${ }^{28}$ and was obtained by ultra-fast scanning calorimetry. The maximum temperature reached on heating was $T_{\max } \approx 944 \mathrm{~K}$, followed by cooling at a rate of $\sim 1090 \mathrm{~K} \mathrm{~s}^{-1}$. The phase transformation was confined to a volume of $\sim 16 \times 0.05 \mu \mathrm{m}^{3}$ (area $\times$ thickness). b Bright-field STEM micrograph and SAED (inset in the top-right corner) of the final microstructure. The white rectangle highlights a B2 grain surrounded mostly by $\mathrm{Cu}_{10} \mathrm{Zr}_{7}$, and it also marks the area of the corresponding fast-Fourier-transform pattern shown as the inset in the bottom-right corner. c HAADF image and the corresponding EDX of the individual elements (Cu: green; Zr: red; and Al: blue) of the area in the B2 crystal vicinity from part $\mathbf{b}$.

two-step crystallization with $T_{\mathrm{x} 1}=750 \mathrm{~K}\left(t_{\mathrm{x} 1}=2.06 \mathrm{~s}\right)$ and $T_{\mathrm{x} 2}=$ $820 \mathrm{~K}\left(t_{\mathrm{x} 2}=2.35 \mathrm{~s}\right)$ corresponding to $\mathrm{Cu}_{10} \mathrm{Zr}_{7}$ and the $\mathrm{B} 2$ phases (Fig. 5a-SAED patterns), respectively. Faster heating could not be achieved inside the TEM. Once the $\mathrm{Cu}_{10} \mathrm{Zr}_{7}$ phase had appeared, it did not grow, unlike the B2 phase, which coarsened until $\sim 944 \mathrm{~K}$. The presence of two minor phases could be distinguished from the SAED patterns: (i) $\mathrm{CuZr}_{2}-$ mostly detected at the initial stages of heating; its appearance agrees with the possible presence of $\mathrm{CuZr}_{2}$ during subcritical $\Phi$ (Fig. 1), although at different stages. It was not possible to detect any time delay between the $\mathrm{Cu}_{10} \mathrm{Zr}_{7}$ and $\mathrm{CuZr}_{2}$ formation in TEM, which conforms to the conventional in situ XRD study of $\mathrm{Cu}_{50} \mathrm{Zr}_{50}$ glass at a heating rate of $10 \mathrm{~K} \mathrm{~min}^{-1}$ by Kalay et al. ${ }^{13}$. (ii) $\mathrm{Cu}_{2} \mathrm{ZrAl}-$ detected at the cooling onset. On cooling, predominantly $\mathrm{Cu}_{10} \mathrm{Zr}_{7}$ phase coarsening without noticeable B2 growth was observed. The $\mathrm{Cu}_{10} \mathrm{Zr}_{7}$ coarsening is evidenced in Supplementary Fig. 11, which shows the integrated temporal evolution of the SAED patterns. Because of the confined crystallization, $T_{\mathrm{x} 1}$ is suppressed by about $100 \mathrm{~K}$ compared to a ribbon ${ }^{28}$, and the delay of $\sim 0.3 \mathrm{~s}$ in the B2 formation is about one order of magnitude longer than for flash-annealing (Fig. 1). A non-monotonic size-dependent crystallization, in terms of $T_{\mathrm{x}}$ and phase selection, was also observed for a sandwiched thin-film $\mathrm{Cu}-\mathrm{Zr}^{36}$ and a Pt-based MG in a form of nanorods with diameters of $<200 \mathrm{~nm}^{37}$.

Mapping the correlation between kinetics and crystallization mechanism. The comprehensive in situ evaluation of the kinetics presented above can be summarized and represented by a Kissinger $\operatorname{plot}^{38}$ (Fig. 6a) and by a continuous-heating-transformation (CHT) diagram (Fig. 6b) for crystallization-which can be correlated with the phase-transformation mechanisms given aboveand by the dependence of $T_{\mathrm{n}}$, and the delay time, $\Delta t$, on $\Delta T$ for levitation (Fig. 6c). $T_{\mathrm{x}}$ is taken from the first XRD pattern when a given phase is detected, which, for a primary phase, typically lies slightly before a recalescence event. Independent of the crystallization mechanism, any present-work primary phase formed superimposes on the overall kinetics by FDSC $^{28}$ at a given $\Phi$ (Fig. 6a, b); some discrepancy arises due to $\Phi$ approximations. Unlike calorimetry measurements, the kinetics of the individual phases can readily be resolved. A Kissinger plot $^{38}$ reflects the temperature-dependent activation energy for crystallization ${ }^{39}$ and by taking the Arrhenius parts it gives $E_{\mathrm{a}}(\mathrm{B} 2)=134 \pm 5 \mathrm{~kJ} \mathrm{~mol}^{-1}$; 

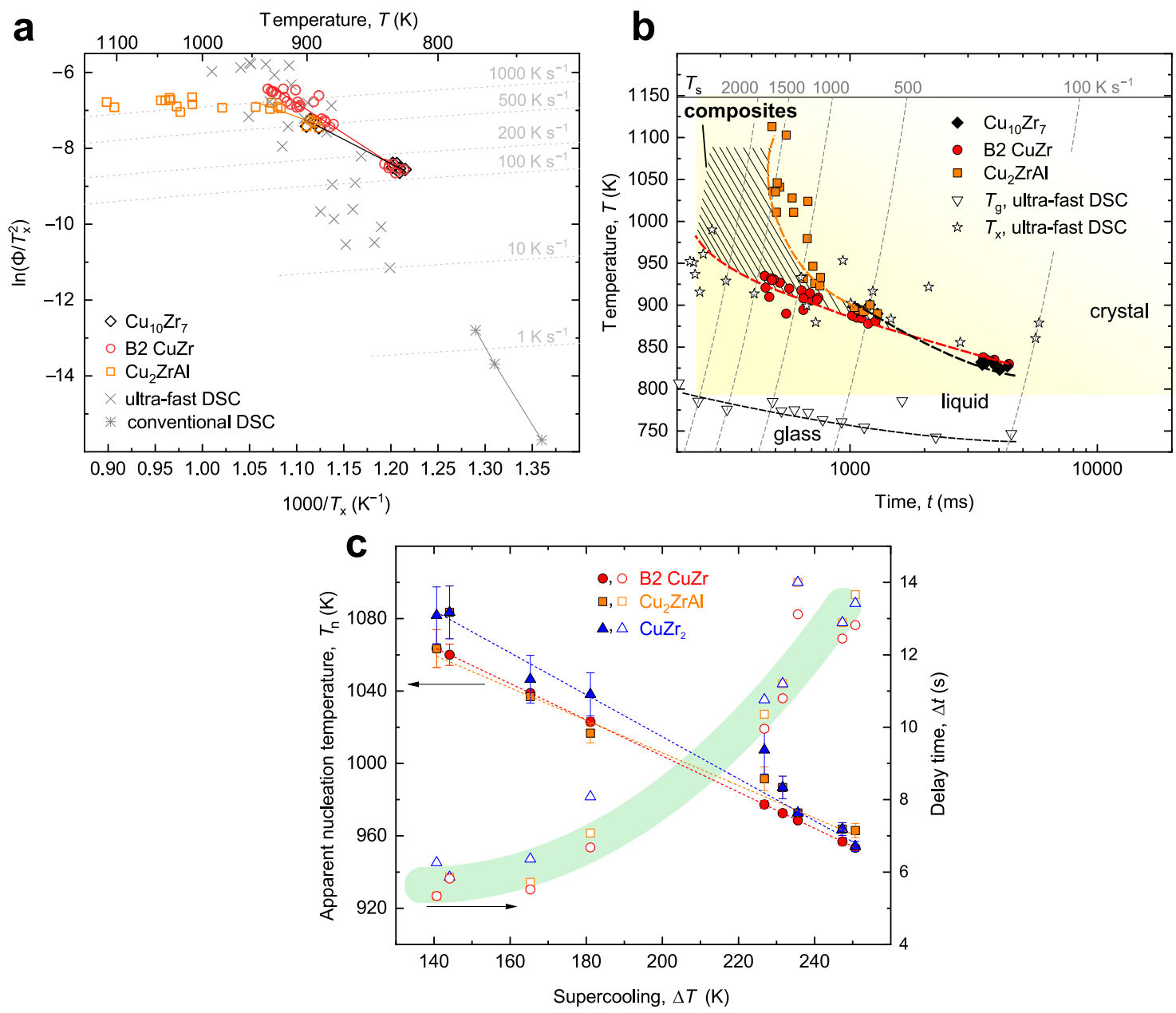

Fig. $\mathbf{6}$ Correlating the kinetics and phase-transformation mechanism in metallic-glass $\mathbf{C u}_{\mathbf{4 7 . 5}} \mathbf{Z r}_{\mathbf{4 7 . 5}} \mathbf{A l}_{\mathbf{5 . 0}}$. a A Kissinger plot for the crystallization of the individual phases during flash-annealing. The $\mathrm{CuZr}_{2}$ phase is not plotted because it could not be unambiguously resolved during flash-annealing. The apparent activation energies for crystallization are shown by the solid lines representing best-fits by assuming Arrhenius kinetics. The ultra-fast-heating (FDSC) and conventional calorimetry data for $T_{x}$ are taken from Cheng et al. ${ }^{28}$ The dashed contours show the nominal heating rates. $\mathbf{b}$ Continuous-heatingtransformation phase diagram for flash-annealing (present work) and for ultra-fast differential scanning calorimetry taken from the literature ${ }^{28}$. Only $T_{g}$ obtained by FDSC is shown as this can be measured more accurately than by flash-annealing. The plotted nominal heating rates in $\mathrm{K} \mathrm{s}^{-1}$ are based on values obtained from FDSC. The range of temperature and heating rate under which ductile composites can be formed during flash-annealing is highlighted by the hatched area. $\mathbf{c}$ The dependence of the apparent nucleation temperature, $T_{\mathrm{n}}$ (left-hand axis-full symbols) and the delay time, $\Delta t-$ defined as $0 \mathrm{~s}$ at $T_{1}$ - (right-hand axis - open symbols) on supercooling $\left(\Delta T=T_{1}-T\right)$ obtained by containerless solidification via electromagnetic levitation. The dashed lines show linear best-fits to the experimental data. For $T_{\mathrm{n}}$ and $\Delta t_{\mathrm{n}}$ at large $\Delta T$, the error bars are smaller than the symbols size.

$E_{\mathrm{a}}\left(\mathrm{Cu}_{10} \mathrm{Zr}_{7}\right)=106 \pm 4 \mathrm{~kJ} \mathrm{~mol}^{-1}$; and $E_{\mathrm{a}}\left(\mathrm{Cu}_{2} \mathrm{ZrAl}\right)=75 \pm 12 \mathrm{~kJ}$ $\mathrm{mol}^{-1}(T<950 \mathrm{~K})$; where $E_{\mathrm{a}}=342 \pm 8 \mathrm{~kJ} \mathrm{~mol}^{-1}$ by taking the conventional DSC only. For $\Phi<500 \mathrm{~K} \mathrm{~s}^{-1}, \mathrm{Cu}_{10} \mathrm{Zr}_{7}$ is the primary phase, and for $\Phi>500 \mathrm{~K} \mathrm{~s}^{-1}$ and higher, the low-temperature phase is suppressed and B2 becomes the primary phase up to the measured $\sim 1500 \mathrm{~K} \mathrm{~s}^{-1}$ and likely extends up to the critical heating rate of $\sim 10,000 \mathrm{~K} \mathrm{~s}^{-1}$ beyond which crystallization is avoided ${ }^{28}$. The lowest $T_{\mathrm{x}}$ at which $\mathrm{Cu}_{2} \mathrm{ZrAl}$ was detected was $\sim 890 \mathrm{~K}$; the $E_{\mathrm{a}}$ leveling off after $950 \mathrm{~K}$ (Fig. 6a) and the nose at $\sim 1050 \mathrm{~K}$ at $\sim 1500$ $\mathrm{K} \mathrm{s}^{-1}$ in CHT (Fig. 6b) suggest that the phase may have reached its maximum transformation rate $^{39}$ and it becomes kinetically suppressed on approaching $T_{s}$. For EML, the solidification is nucleation-dominated for all phases that formed from the supercooled liquid. The solidification mechanism was nearly independent of $\Delta T$ in the range $141-251 \mathrm{~K}$, where the latter corresponds to $953 \mathrm{~K}\left(0.83 T_{\mathrm{s}}\right)$ which lies below the expected maximum in the polymorphic crystal-growth rate at $\sim 1000 \mathrm{~K}^{40,41}$. There was a tendency for $\mathrm{Cu}_{2} \mathrm{ZrAl}$ to nucleate before the $\mathrm{CuZr}_{2}$ phase at smaller $\Delta T$, whereas they formed in parallel at larger $\Delta T$. The largest $\Delta T$, a relative $\Delta T / T_{1}=0.21$, is smaller than that achieved for $\mathrm{Cu}_{50} \mathrm{Zr}_{50}$ liquid via electrostatic levitation ${ }^{42}$.

Nanostructure and composition of the transformed systems. The in situ TEM, Fig. 5, showed that the final microstructure remained partially amorphous (SAED in Fig. 5b, top-right corner; and see also Supplementary Fig. 12 in Supplementary Information which shows an HRTEM image from one of the largest amorphous regions and the corresponding SAED pattern), and these regions probably separate the $\mathrm{B} 2$ crystals from $\mathrm{Cu}_{10} \mathrm{Zr}_{7}$ grains. A B2 crystal, oriented close to the [100] zone axis, is in the center of Fig. 5b (marked by the rectangle) and is surrounded by $\mathrm{Cu}_{10} \mathrm{Zr}_{7}$ crystals. EDX of the CuZr crystal confirmed a 50.5:49.5 $( \pm 0.5$ at.\%) ratio. There were some regions with a higher atomic fraction of $\mathrm{Zr}$ in comparison with $\mathrm{Cu}$, yet, their origin remained unclear and they seemed to spatially correlate with the amorphous regions. Most notably, precipitation of $\mathrm{Al}$ around the B2 crystal could be detected (Fig. 5c, bottom-right image). 

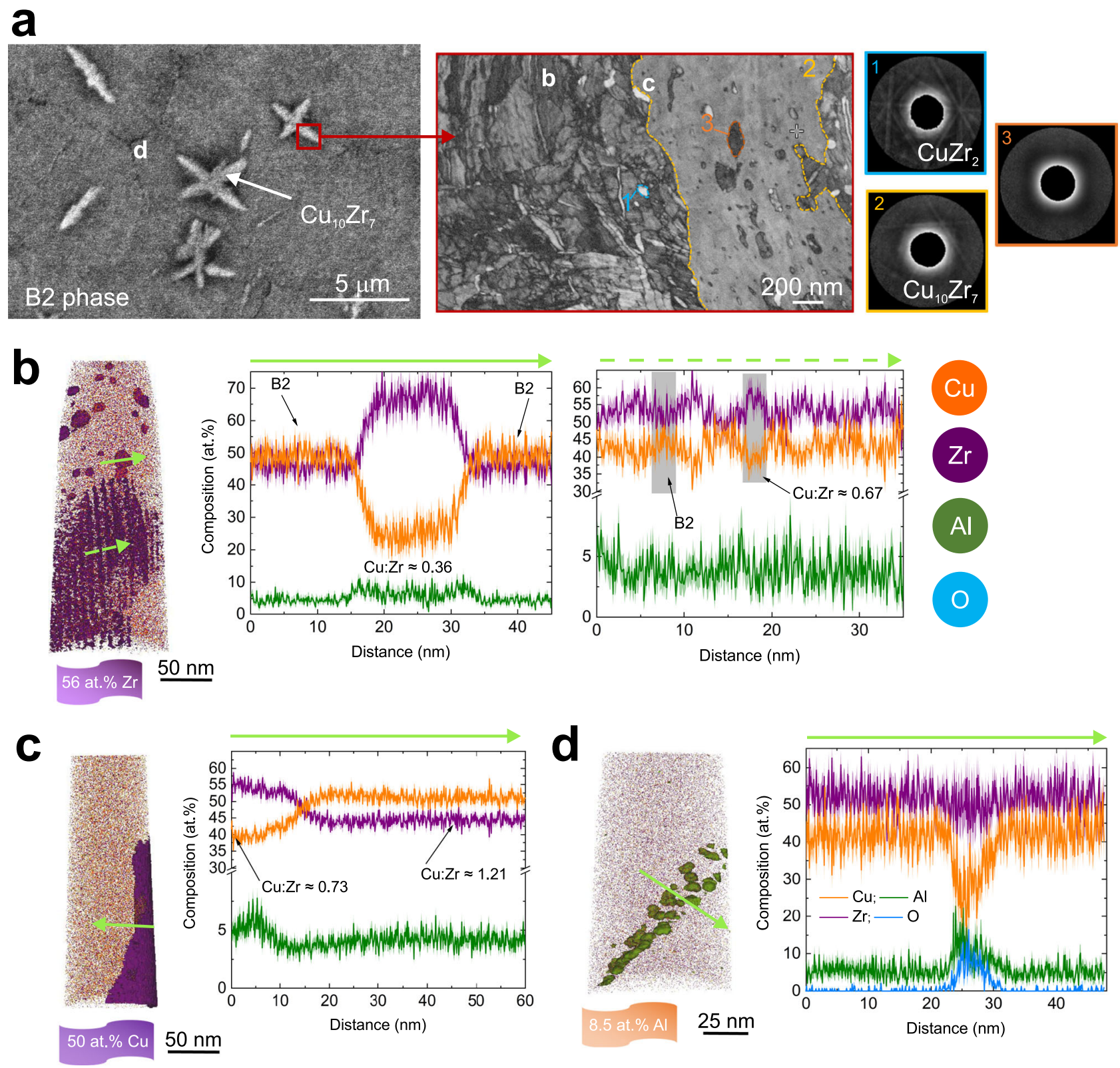

Fig. 7 Atom probe tomography reconstructions of the local microstructure after flash-annealing at a supercritical-heating rate as shown in Fig. 2. a Left: SEM micrograph of an area from which APT samples were extracted. Middle: Transmission Kikuchi diffraction image quality map showing details of the interface between $\mathrm{Cu}_{10} \mathrm{Zr}_{7}$ (the region enclosed by the yellow borderline) and $\mathrm{B} 2$ phases (uncolored); the latter contains $\mathrm{CuZr} 2$ phase (the region enclosed by the blue borderline). Right: Individual Kikuchi patterns taken from the mapping depicted in the middle (blue: $\mathrm{CuZr}_{2}$, yellow: $\mathrm{Cu}_{10} \mathrm{Zr}_{7}$, orange: amorphous). The letters in the left and the middle micrographs mark different regions where the APT samples illustrated in $\mathbf{b}$-d were extracted from. $\mathbf{b}$ 3-D atom map showing precipitates within the B2 matrix and a local eutectoid microstructure consisting of linear features arranged as a plane with the corresponding 1-D concentration profiles. c 3-D atom map of a region dominated by $\mathrm{Cu}_{10} \mathrm{Zr}_{7}$ phases is shown together with the corresponding 1-D concentration profile. d Aluminum precipitation within the B2 crystal and the corresponding 1-D concentration profile.

A representative SEM micrograph of a polycrystalline sample after flash-annealing in vacuum shows dendrites of $\mathrm{Cu}_{10} \mathrm{Zr}_{7}$ phase surrounded by spheroidal grains of B2 (Fig. 7a; a lowermagnification micrograph is presented in Supplementary Fig. 13). The surface density of nuclei, $N_{s}$, calculated from a high-speed video taken in situ by camera ${ }^{30}$ was nearly constant $\sim(0.2-1.2) \times$ $10^{5} \mathrm{~m}^{-2}$ (Supplementary Fig. 14) in the range of $50-950 \mathrm{~K} \mathrm{~s}^{-1}$. Similar independence of $N_{\mathrm{s}}$ on isothermal annealing temperature was observed in oxide-based glass-forming liquids $\mathrm{s}^{4}$. The volume nuclei density decreased from $1.23 \times 10^{17}$ to $2.63 \times 10^{16} \mathrm{~m}^{-3}$ with increasing $\Phi$ (Supplementary Fig. 14). Although this contrasts with the usual trend, at least within the range of conventional $\Phi$, similar $N_{\mathrm{v}}-\Phi$ dependence was reported for flash-annealed $\mathrm{Cu}_{44} \mathrm{Zr}_{44} \mathrm{Al}_{8} \mathrm{Hf}_{2} \mathrm{Co}_{2}$ bulk MG by Kosiba et al. ${ }^{16}$, who suggested a lower effective nucleation rate during flash-annealing than for steady-state conditions.

Based on the APT analysis, no chemical heterogeneities were detected in the as-spun ribbon. The bulk composition of $\mathrm{Cu}_{46.5} \mathrm{Zr}_{47.0} \mathrm{Al}_{5.3}$ (Supplementary Fig. 15) was measured which is close to nominal. The difference of $\sim 1.5$ at.\% can be attributed to measurement errors and to the presence of trace elements such as oxygen and hydrogen. APT samples of the flash-annealed glasses were taken from the vicinity of the $\mathrm{Cu}_{10} \mathrm{Zr}_{7} / \mathrm{B} 2$ interface by site-specific FIB lift-out preparation. The locations are labeled 
by the corresponding letters and presented in Fig. 7, parts (b), (c), and (d) for vacuum-heated glasses. A supercritical-heating rate of $\sim 900 \mathrm{~K} \mathrm{~s}^{-1}$ to predominantly from the B2 phase was used, which conforms to the thermal history shown in Fig. 2 without the melting step. The maximum temperature was $1050 \mathrm{~K}, \sim 75 \mathrm{~K}$ above $T_{\mathrm{e}}$. Local Kikuchi mapping showed that some parts remained amorphous (Fig. 7a-orange Kikuchi pattern), which conforms to the TEM observations (Fig. 5b and Supplementary Fig. 12). Some regions of the material contained unindexed crystallization phases because mapping with extremely low confidence indexing was excluded. The yellow region highlights the indexed area of a macroscopic $\mathrm{Cu}_{10} \mathrm{Zr}_{7}$ region surrounded by the $\mathrm{B} 2$ phase (uncolored). A small amount of $\mathrm{CuZr}_{2}$ phase was identified-highlighted in blue (Fig. 7a). Different microstructural features were identified in APT reconstructions. The APT sample matrix consisted of the $\mathrm{B} 2$ phase with a composition close to 1:1 $\mathrm{Cu}: \mathrm{Zr}$ ratio (Fig. 7b; see Supplementary Fig. 16 for chemical analysis). There were two kinds of $\mathrm{Zr}$-rich precipitates in the B2 matrix: spheroidal particles of up to $\sim 20 \mathrm{~nm}$ in diameter with the atomic ratio $\mathrm{Cu}: \mathrm{Zr} \approx 0.36$ (Fig. $7 \mathrm{~b}$ ) and, in some samples, eutectoid-like structures (lamella thickness of $\sim 5 \mathrm{~nm}$ ) consisting of lamellae with nearly equiatomic $\mathrm{CuZr}$ composition and with $\mathrm{Cu}: \mathrm{Zr} \approx 0.67$ ratio. The latter ratio represents some transient (metastable) composition, frozen-in states on the way to the equilibrium phases, and it is close to that in $\mathrm{Cu}_{5} \mathrm{Zr}_{8}$ (Cu:Zr $=$ $0.63)$ whose existence in the binary glass is still in dispute in the literature ${ }^{13}$. Also, $\mathrm{Zr}$-rich precipitates with $\mathrm{Cu}: \mathrm{Zr} \approx 0.73$ ratio could be identified located at the interface between B2 phase and $\mathrm{Cu}_{10} \mathrm{Zr}_{7}$ dendrites (Fig. $7 \mathrm{c}$ ). The $\mathrm{Cu}: \mathrm{Zr}$ atomic ratio in the $\mathrm{Cu}$-rich phase at the interface was $\approx 1.21$, which corresponds to slight $\mathrm{Cu}$ deficiency of the nominal $\mathrm{Cu}_{10} \mathrm{Zr}_{7}(\mathrm{Cu}: \mathrm{Zr}=1.43)$ phase. All of these reveal a possible tendency towards the formation of $\mathrm{CuZr}_{2}$ phase along with $\mathrm{Cu}_{10} \mathrm{Zr}_{7}$ phase. Interestingly, Al-enriched precipitates with a diameter of $<10 \mathrm{~nm}$, containing up to $\sim 12$ at. $\%$ of $\mathrm{Al}$, were typically located along the internal boundaries within the B2 phase (Fig. 7d). The local Al precipitation conforms to that revealed by TEM around the B2 crystal (Fig. $5 \mathrm{c}$ ).

A $\mathrm{ZrO}_{x}$ layer (Supplementary Fig. 17), $\sim 20 \mathrm{~nm}$ thick, was found at the interface shown in Fig. 7c, while no macroscopic oxides were observed by XRD, though $\mathrm{Cu}-\mathrm{Zr}$-based MGs are prone to oxidation ${ }^{44}$. A detailed study of the surface conditions by Auger and XPS analysis found that for the pristine surface the $\mathrm{Zr3d}$ binding energy revealed $\mathrm{Zr}$ in the form of an oxide and $\mathrm{Cu} 2 \mathrm{p}$ was metallic. Down to a depth of a few nanometers, $\mathrm{Zr} 3 \mathrm{~d}$ existed in two oxidation states as an oxide and metal, while Cu2p remained metallic (Supplementary Figs. 18 and 19 showing Auger and XPS spectra, respectively). The oxide thickness decreased from $\sim 15$ to $\sim 10 \mathrm{~nm}$ as $\Phi$ increased. The glass properties are oxygen-sensitive-higher oxygen content may have a strong influence on the balance between surface and volume crystallization ${ }^{43}$; it reduces the glass-forming ability and suppresses the $\mathrm{B} 2$ phase growth ${ }^{45}$, therefore higher critical heating rate has to be applied to obtain predominant $\mathrm{B} 2$ phase for glasses with a higher content of oxygen.

Representative SEM micrographs of glasses heated under helium are shown in Fig. 8a and Supplementary Fig. 20. APT samples were taken from the interface between the dendritic and spheroidal grains (Fig. 8a). APT reconstruction of a pure B2 phase confirmed the nearly equimolar composition (Fig. 8a-the B2 matrix) conforming to vacuum heating. Detailed analysis of the interface found a compact oxide layer of $\mathrm{ZrO}_{x}, \sim 20 \mathrm{~nm}$ thick (Fig. 8a), which was more pronounced than in the vacuumheated ribbons. Auger spectroscopy confirmed the oxide layer of $<20 \mathrm{~nm}$ thick (Supplementary Fig. 21). The chemical nature of $\mathrm{Zr}$ and $\mathrm{Cu}$ conformed to those before and after sputtering found during vacuum heating (Supplementary Fig. 19). Below the oxide layer, $\mathrm{Cu}$-rich and $\mathrm{Zr}$-rich phases were found. The former phase atomic ratio was $\mathrm{Cu}: \mathrm{Zr} \approx 1.38$, which is close to that of $\mathrm{Cu}_{10} \mathrm{Zr}_{7}$, and the latter was $\mathrm{Cu}: \mathrm{Zr} \approx 0.63$, resembling, as in a vacuum, the ratio in the speculated $\mathrm{Cu}_{5} \mathrm{Zr}_{8}$ phase (Fig. $\left.8 \mathrm{~b}\right)^{13}$. Because of the complex, non-planar interface morphology, different compositions could be mapped including one suggestive of the hightemperature $\mathrm{Cu}_{2} \mathrm{Zr}$ phase, $<5 \mathrm{~nm}$ thick (Fig. $8 \mathrm{a}$ ). As for vacuum heating, local Al-enriched precipitates, $\sim 10$ at.\% and less of $\mathrm{Al}$ could be found in the B2 matrix (Fig. 8a).

\section{Discussion}

In situ XRD under isothermal annealing $(T=671 \mathrm{~K}, t=37$ $\min )^{12}$ and at conventional ${ }^{13} \Phi=10 \mathrm{~K} \mathrm{~min}^{-1}$ of the equimolar $\mathrm{Cu}_{50} \mathrm{Zr}_{50}$ glass, often used as the prototype crystallization mechanism, suggested that fine $\mathrm{Cu}_{10} \mathrm{Zr}_{7}$ particles are formed during primary crystallization; on prolonged annealing $\mathrm{Cu}_{10} \mathrm{Zr}_{7}$ grows, accompanied by solute partitioning leading to $\mathrm{Zr}$ enrichment in the glass. This is followed by the appearance of $\mathrm{CuZr}_{2}$, which is quickly terminated when $<20 \mathrm{~nm}$ thick, and which already templates the B2 phase growth during primary crystallization. The B2 then dissolves and re-precipitates at $1002 \mathrm{~K}$ on heating ${ }^{13}$.

Here, we provide direct experimental evidence that the crystallization mechanism originally suggested for the equimolar binary glass can only be extended to ternary systems and to higher $\Phi$ with caution. The proposed templated-growth mechanism of the B2 phase could not be clearly resolved, although, especially fur subcritical $\Phi$ it is reasonable to suggest that the dendrites are located at the center of $\mathrm{B} 2$ grains (Supplementary Fig. 13) and $\mathrm{Cu}_{10} \mathrm{Zr}_{7}$ particles could act as nuclei for the B2 phase. For flash-annealing, all phases formed directly from the supercooled liquid, there were no detectable solid-state transformations, and no B2 re-precipitation could be observed. The B2 phase did not undergo any detectable martensitic transition to the previously reported B19' and B33 two-phase structure $^{13,46}$. The in situ XRD (Figs. 1, 2, for vacuum and Fig. 3 for He-atmosphere heating) did not reveal any eutectoid reaction of $\mathrm{Cu}_{10} \mathrm{Zr}_{7}+3 \mathrm{CuZr}_{2} \rightarrow 13 \mathrm{CuZr}$; only local eutectoidlike microstructure could be revealed in some samples by APT. As shown in Fig. 7b, a local fine-scale eutectoid microstructure of alternating $\mathrm{B} 2$ and $\mathrm{Zr}$-rich phases can exist, the latter probably locally compensating for the formation of $\mathrm{Cu}_{10} \mathrm{Zr}_{7}$ phase; also, local variations in the composition and cooling rates may exist. Arguably, both flash-annealing XRD and TEM (for the latter a strong phase selection due to nanoconfined crystallization cannot be ruled out) only hint at the presence of $\mathrm{CuZr}_{2}$ phase during heating/cooling. The absence of the $\mathrm{CuZr}_{2}$ phase on heating would contradict highly sensitive calorimetry experiments where the eutectoid reaction in a thin-film equimolar CuZr glass could be resolved even on fast heating $\left(\Phi \approx 21,000 \mathrm{~K} \mathrm{~s}^{-1}\right)^{25,47}$. On the other hand, the APT reconstructions revealed the presence of a different $\mathrm{Zr}$-rich phase, where the $\mathrm{Cu}: \mathrm{Zr}$ ratio resembled that of $\mathrm{Cu}_{5} \mathrm{Zr}_{8}{ }^{13}$. The compositions from APT should not be simplified by using binary chemistry only. Clearly, $\mathrm{Al}$ is always present in the quoted phases, but no tendency to phase separation in the glass, as in an Al-rich $\mathrm{MG}^{48}$, and no composition resembling, for example, that of $\mathrm{Cu}_{2} \mathrm{ZrAl}$ in the composite were found. There was a clear tendency to partition $\mathrm{Al}$ from the $\mathrm{B} 2$ phase, but not from the other phases: an Al-enrichment, with thickness $<10 \mathrm{~nm}$, around the nanoconfined B2 phase boundary was found by TEM (Fig. 5c); and Al-enriched precipitates, with diameter less than $\sim 10 \mathrm{~nm}$, containing up to $\sim 12$ at.\%, were typically observed along the internal boundaries within the B2 spheroid by APT (Figs. 7d and 8a). Generally, Al helps to improve the glass-forming ability ${ }^{49}$, and its partitioning supports the fast polymorphic 

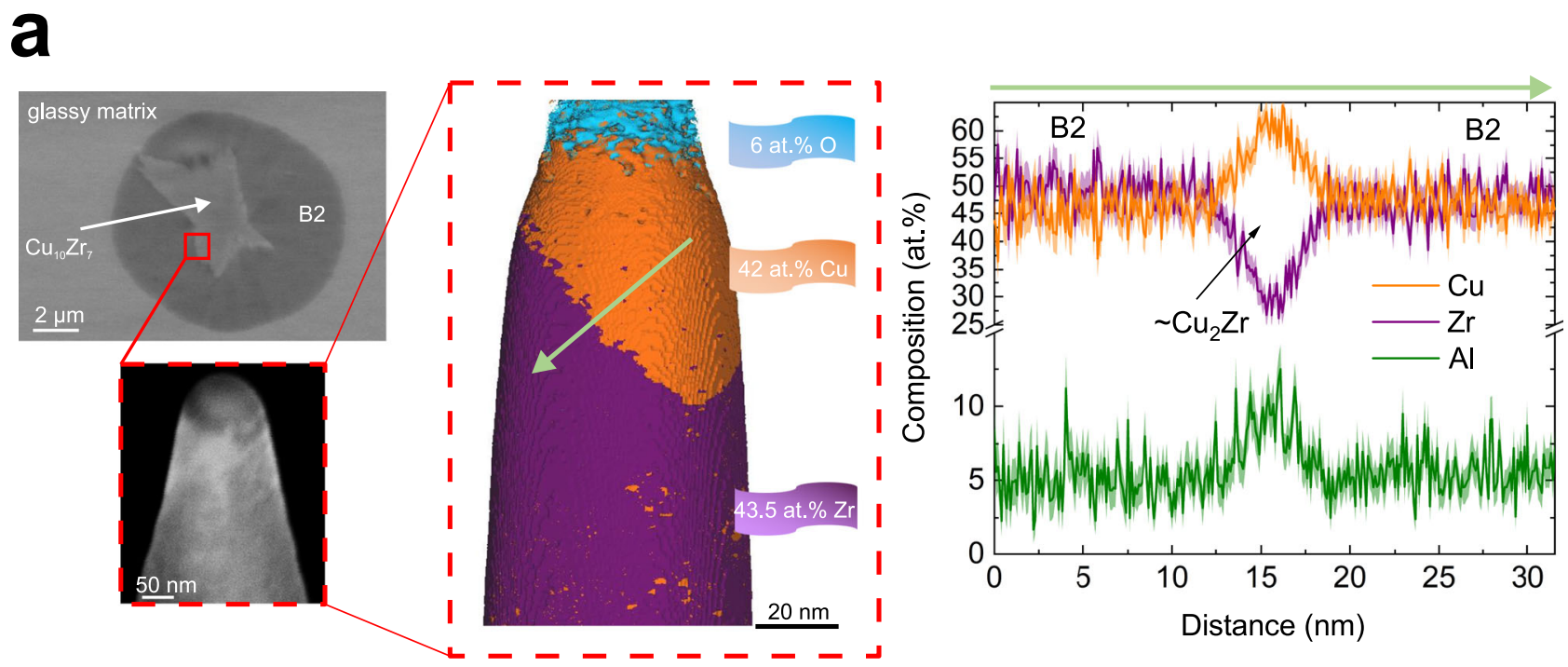

b
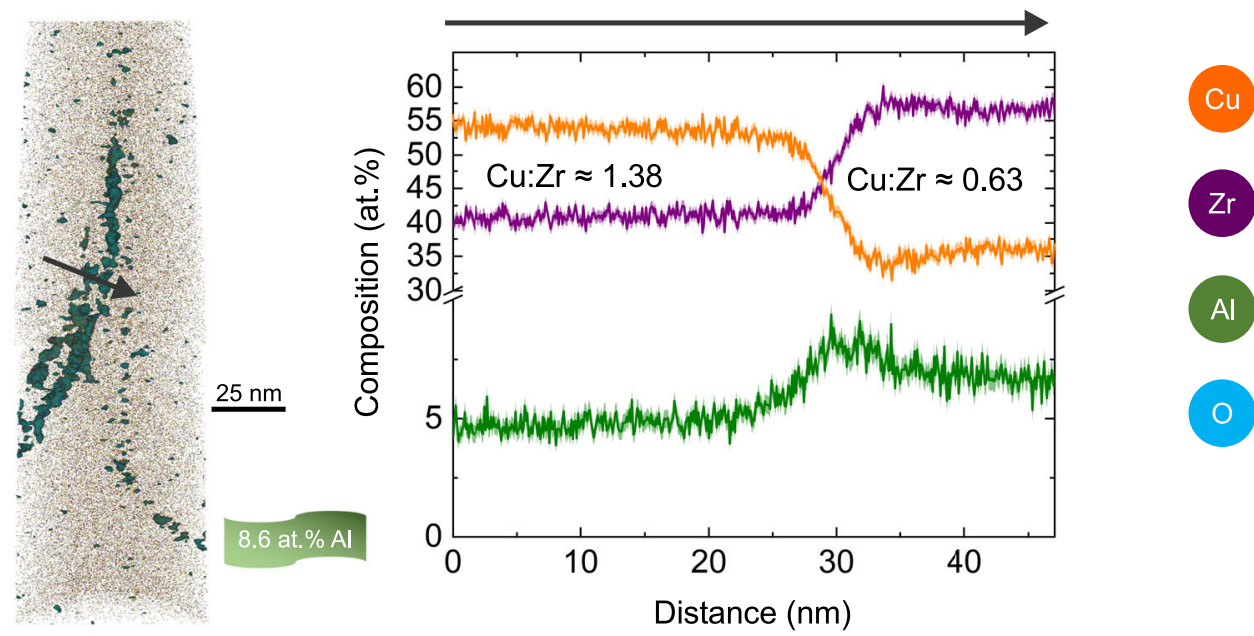

Fig. 8 Atom probe tomography reconstructions of the local microstructure of a metallic-glass-crystal composite formed in a chamber fluxed with He. a Left: SEM micrographs showing the B2 (spheroid)/ $\mathrm{Cu}_{10} \mathrm{Zr}_{7}$ (dendrite) interface from which an APT sample was prepared. Middle: APT volume rendering of the interface. Right: The corresponding 1-D concentration profile. $\mathbf{b}$ APT volume rendering of Al from a different region and showing the precipitation.

growth of the B2 phase. Also, aluminum is highly mobile; the selfdiffusion coefficient is $7.2 \times 10^{-9} \mathrm{~m}^{2} \mathrm{~s}^{-1}$ at $T=980 \mathrm{~K}^{50}$, and this is high enough to permit strain-induced intermixing ${ }^{51}$ and the formation of pure $\mathrm{Al}$ nanocrystals ${ }^{52}$ inside shear bands. Interestingly, for the equimolar binary glass, recent APT work showed a tendency to the formation of the equilibrium $\mathrm{Cu}_{10} \mathrm{Zr}_{7}$ and $\mathrm{CuZr}_{2}$ phases in shear bands on deformation at room and nominal $80 \mathrm{~K}$ temperature ${ }^{53}$.

Under what conditions can ductile composites be made? A critical $\Phi$ relevant for the composites is $\sim 500 \mathrm{~K} \mathrm{~s}^{-1}$ and higher (Fig. 6b). Below that value, $\mathrm{Cu}_{10} \mathrm{Zr}_{7}$ precedes the $\mathrm{B} 2$-phase formation. $\mathrm{B} 2$ becomes the primary and dominant phase followed by $\mathrm{Cu}_{2} \mathrm{ZrAl}$ at a higher temperature, whose formation is quickly suppressed beyond $\sim 1500 \mathrm{~K} \mathrm{~s}^{-1}$. Although $\mathrm{Cu}_{10} \mathrm{Zr}_{7}$ could not be detected at high $\Phi$, probably because of low X-ray sensitivity, it may be that some nuclei of $\mathrm{Cu}_{10} \mathrm{Zr}_{7}$ may still be present, whether existing predominantly on the surface or in the volume remains unclear, which can grow on consequent cooling. To obtain composites with a maximized fraction of the $\mathrm{B} 2$ phase on heating, a minimum $\Phi$ of $\sim 1500 \mathrm{~K} \mathrm{~s}^{-1}$ should be applied, giving $T_{\mathrm{x}}$ $\sim 930 \mathrm{~K}$. Such a high $\Phi$ gives a relatively narrow temperature range of $\sim 200 \mathrm{~K}$ for which the upper-limiting temperature can be controlled before melting is reached. The other way to control the composite formation is by flash-annealing in a chamber flushed with helium. The efficient cooling gives much better control of the upper-limiting temperature, suppresses the possible unwanted phase transformation on cooling, and gives composites with a lower fraction of $\mathrm{Cu}_{10} \mathrm{Zr}_{7}$, though its formation could not be fully avoided. No local eutectoid-like microstructure could be found under He atmosphere, and it is known that when B2 phase is cooled sufficiently fast such decomposition can be avoided or suppressed in the binary $\mathrm{MG}^{47}$. The helium atmosphere helps to avoid the temperature overshoot around $T_{\mathrm{x}}$ which would quickly result in fully crystalline samples.

The high propensity of the glass for the B2 phase formation seems to stem from the following factors: (i) kinetics-higher $\Phi$ promotes polymorphic crystallization; (ii) chemistry-local Alenrichments are induced on crystallization resulting in having the B2 phase close to 50:50 ratio, i.e., the only composition corresponding to the equilibrium to be found among the crystallization products; (iii) atomic packing-there is effectively no difference in the number density between CuZr B2 crystal $\left(0.0576 \AA^{-3}\right)$ and 
$\mathrm{Cu}_{47.5} \mathrm{Zr}_{47.5} \mathrm{Al}_{5.0}$ glass $\left(0.0577 \AA^{-3}\right)$, while the number density of $\mathrm{Cu}_{10} \mathrm{Zr}_{7}\left(0.0609 \AA^{-3}\right)$ and $\mathrm{CuZr}_{2}\left(0.0518 \AA^{-3}\right)$ phases is, respectively, $\approx 5.5 \%$ and $\approx 10.2 \%$ smaller $^{54}$. Therefore, the formation of $\mathrm{Cu}_{10} \mathrm{Zr}_{7}$ and/or $\mathrm{CuZr}_{2}$ phase in the glassy matrix may result in significant raise of local stress; and (iv) atomic structure -there is a close resemblance for the $\mathrm{Cu}-\mathrm{Zr}$ atomic pairs in the first-coordination shell of the glass and the B2 phase as shown in the structural study elsewhere ${ }^{54}$. Interestingly, composites containing the nanocrystalline B2 phase can be obtained through thermal cycling of the ternary glass between room and liquidnitrogen temperature ${ }^{55}$-supporting the high propensity of the glass for the B2 phase formation.

To conclude, the mechanism of crystallization and solidification could be correlated in situ with phase-transformation kinetics and related to the formation of ductile metallic-glass-crystal composites on flash-annealing of $\mathrm{Cu}_{47.5} \mathrm{Zr}_{47.5} \mathrm{Al}_{5.0}$ glass. A complex CHT diagram was directly obtained, unlike the former projections based on CuZr phase equilibria. The primary onset parameters, namely crystallization time and temperature, clearly correlate with the former kinetics measurements obtained via ultra-fast-heating calorimetry. For calorimetry, the kinetics could not be understood in terms of the crystallization mechanism of individual phases and no high-temperature phase transformations following the primary crystallization could be detected. The B2 phase, beneficial for plasticity, becomes the primary crystallization phase when $\Phi$ is $500 \mathrm{~K} \mathrm{~s}^{-1}$ and higher. Such a critical rate exceeds that for the low-temperature phase $\mathrm{Cu}_{10} \mathrm{Zr}_{7}$ to be kinetically suppressed, though it cannot be fully avoided in the final composites. EML evidenced the presence of the $\mathrm{CuZr}_{2}$ phase, which can be expected on fast heating, but it could not be unambiguously resolved in the high-energy X-ray patterns of flash-annealing, by in situ TEM or by APT. On the other hand, higher rates of $\sim 1500 \mathrm{~K} \mathrm{~s}^{-1}$ are needed to get better control of the crystallization sequence upon which the brittle high-temperature $\mathrm{Cu}_{2} \mathrm{ZrAl}$ phase is suppressed. The lowest temperature at which $\mathrm{Cu}_{2} \mathrm{ZrAl}$ formed was $\sim 890 \mathrm{~K}$. So, both the low- and the high-temperature phases need to be suppressed on heating. The eutectoid crystallization mechanism suggested for the prototype binary $\mathrm{Cu}_{50} \mathrm{Zr}_{50}$ glass was not identified by the in situ XRD, but a local nanometer-lengthscale eutectoid structure consisting of alternating B2 and Zr-rich phase was identified by APT. Because of the unwanted $\mathrm{Cu}_{10} \mathrm{Zr}_{7}$ formation on cooling, the $\mathrm{B} 2$ fraction can be enhanced by employing heating in $\mathrm{He}$ atmosphere to achieve a cooling rate of $1000-2000 \mathrm{~K} \mathrm{~s}^{-1}$.

One way the glass increases its propensity for B2 phase formation is by partitioning $\mathrm{Al}$ from the growing crystals to form locally Al-enriched precipitates, $<10 \mathrm{~nm}$ in diameter, and containing up to 12 at.\% of Al. Such a kinetic mechanism of $\mathrm{Al}$ precipitation is still pronounced even when fast cooling is achieved in a chamber flushed with helium. Because of highly non-equilibrium conditions of flash-annealing, mainly metastable compositions were detected. The multi-technique approach used in this work can be applied to map phase transformations in other metallic-glass-forming systems and to understand the phase-transformation kinetics in order to control processing parameters to form composites with enhanced ductility.

\section{Methods}

Sample preparation. A pre-alloy of $\mathrm{Cu}_{47.5} \mathrm{Zr}_{47.5} \mathrm{Al}_{5.0}$ (at.\%) was prepared from high-purity elements $(\geq 99.99 \%)$ by arc-melting in Ti-gettered Ar-atmosphere. Each ingot was re-melted three times to ensure chemical homogeneity. The ribbon $(\sim 30 \mu \mathrm{m}$ thick and $\sim 2 \mathrm{~mm}$ wide) was melt-spun from the master alloy at $T \approx 1320 \mathrm{~K}$ on a $\mathrm{Cu}$ wheel rotating with a peripheral speed of $29 \mathrm{~m} \mathrm{~s}^{-1}$.

Flash-annealing and in situ synchrotron experimental setups. Details of the constant-current resistive-heating device and its implementation into a highenergy X-ray beam at DESY, Hamburg, are given in ref. ${ }^{30}$ Ribbons were resistively heated in a constant-current mode by using a Delta Elektronika SM 52-30 power supply. Ribbon surface temperature was monitored by using a LumaSense IGA $320 / 23$-LO pyrometer with a temporal resolution of $2 \mathrm{~ms}$ (in analog mode) and calibrated on the known melting point of the glass. All signals were acquired by a National Instruments USB-6211 acquisition card-data were collected at a sampling rate of up to $48 \mathrm{kS} \mathrm{s}^{-1}$. The typical error in the measured resistance was $<0.5 \%$. All heating experiments were carried out in transmission mode either in a vacuum of $10^{-4}$ mbar or in a chamber flushed with helium $(6 \mathrm{~N})$ at $5 \mathrm{~cm}^{3} \mathrm{~min}^{-1}$ to control cooling. High-energy X-ray diffraction was done in situ at the P21.1 beamline (wavelength $0.1204 \AA$, beam size $\sim 900 \times 900 \mu \mathrm{m}^{2}$ ). Scattered intensities were captured using a hybrid pixel Dectris PILATUS3 X CdTe $2 \mathrm{M}$ detector (pixel size $172 \times 172 \mu \mathrm{m}^{2}$ ) operated at $250 \mathrm{~Hz}$. The sample-to-detector distance was $1021 \mathrm{~mm}$ for vacuum heating (Figs. 1 and 2) and $1412 \mathrm{~mm}$ for heating under $\mathrm{He}$ (Fig. 3). Diffractograms were derived from the recorded 2-D patterns by azimuthal integration using the Fit2D v17.006 software ${ }^{56-58}$. The diffraction patterns of individual phases are taken as: ICDD PDF number 00-047-1028 for $\mathrm{Cu}_{10} \mathrm{Zr}_{7}$ phase; ICSD collection code 103163 for B2 phase; ICSD collection code 656062 for $\mathrm{Cu}_{2} \mathrm{ZrAl}$ phase; and ICSD collection code 151846 for $\mathrm{CuZr}_{2}$ phase. Rietveld refinement was done in HighScore Plus ${ }^{59} 4.7$ a (built 4.7.1.25061) by using ICCD database versions PDF- $4+2019$ and PDF- $4+2020$.

Electromagnetic levitation. Details of the EML device used for the measurements can be found in ref. ${ }^{60}$ Metallic-glass samples of weight $0.5-0.7 \mathrm{~g}$ were used. The EML chamber was initially evacuated to $5 \times 10^{-5}$ mbar and then re-filled with a high-purity He gas up to a pressure of 500-700 mbar. Glass heating and positioning were controlled via a water-cooled copper coil powered by a $10-\mathrm{kW}$ generator operating at $280 \mathrm{kHz}$; the sample was cooled by recirculating the inert gas across the sample with a flow of up to $281 \mathrm{~min}^{-1}$; while maintaining levitation, samples could be cooled down to $\sim 780 \mathrm{~K}$. The temperature was monitored by a pyrometer, implemented in a LASCON Process Controller LPC03 unit, with a temporal resolution of $20 \mathrm{~ms}$ and this was calibrated on the known liquidus temperature of the alloy, $T_{1}=1204 \mathrm{~K}$.

The high-energy X-ray scattering experiments were carried out in transmission geometry, the beam energy was $101.537 \mathrm{keV}$ (corresponding to a wavelength of $0.1221 \AA$ ), and data were collected using a hybrid pixel Dectris PILATUS3 X CdTe $2 \mathrm{M}$ detector (pixel size $172 \times 172 \mu \mathrm{m}^{2}$ ) operated at 5-50 Hz. The sample-todetector distance was $1100 \mathrm{~mm}$. Diffractograms were derived from the recorded 2$\mathrm{D}$ patterns by azimuthal integration using the Fit2D v17.006 software ${ }^{56-58}$.

In situ transmission electron microscopy. A cross-sectional specimen with a final thickness of $50-100 \mathrm{~nm}$ was prepared by FIB milling using a Helios Nanolab FIB/ SEM (Thermo Fisher Scientific). This specimen was transferred from the ribbon sample to a windowed point on a chip (DENSsolutions). A thin layer of platinum (thickness of $200 \mathrm{~nm}$ ) was deposited over the target area using an electron beam before the ion-beam exposure. A standard in situ procedure was adopted for liftout. The sample was secured on the chip with the stage at $45^{\circ}$ tilt (in-plane to the chip membrane) with ion-beam-deposited platinum. The chip was then re-oriented with the stage at $10-16^{\circ}$ for thinning of the thin foil. Further thinning was conducted until the platinum appeared transparent in a $5 \mathrm{kV}$ electron-beam image, indicating a thin-foil thickness of $\sim 150 \mathrm{~nm}$. The final thinning was at a reduced voltage of $2 \mathrm{kV}$ to a final electron transparency at $3 \mathrm{kV}$ electron energy. This procedure minimizes the amount of damaged material and reduces the levels of implanted gallium in the final thin foil.

The image and diffraction acquisition and spectroscopic analysis were conducted using a Tecnai Osiris TEM/STEM (FEI) with field-emission gun operated at $200 \mathrm{keV}$, equipped with a Super-X windowless EDX detector. In situ study was carried out by using a heating holder (DENSsolutions) under the usual TEM vacuum $\left(<10^{-8} \mathrm{mbar}\right)$. The resistance of the platinum coil in the chip is monitored in a four-point configuration, and the temperature was calculated using calibration constants provided by the manufacturer. The heating holder allowed for controlling the sample temperature with a temperature accuracy of $>95 \%$, a temperature homogeneity of $>99.5 \%$, and thermal stability of $0.005 \mathrm{~K}$. The details of the calibration are given in ref. ${ }^{35}$ The temperature ramp had a duration of $3 \mathrm{~s}$ for heating and $0.6 \mathrm{~s}$ for cooling. Time-series data of SAED diffractions were recorded with an acquisition time of $0.1 \mathrm{~s}$. SAED patterns and associated images were acquired with a Gatan US1000 charge-coupled device camera. The SAED aperture was $\sim 200 \mathrm{~nm}$, and the camera length was set to cover the high- $Q$ range up to $12.2 \AA^{-1}$. Due to the absence of thermal drift, data acquisition could be performed during the high-speed heating and cooling process. The chemical composition was analyzed using the EDX detector after crystallization at room temperature.

Atom probe tomography. Specimens for APT analysis were prepared on a FEI Helios Nanolab 600 focused ion beam milling instrument equipped with a Ga source. APT experiments were carried out on CAMECA LEAP 5000 XR and XS instruments. The atom probe was operated in a laser pulse mode using a repetition rate of $125 \mathrm{kHz}$, pulse energy of $40 \mathrm{pJ}$, and samples at a temperature of $60 \mathrm{~K}$. Subsequent APT data reconstruction and post-processing were done using the commercial IVAS 3.8.4 software. Regions containing high and low compositions of 
different elements were identified by reconstruction via an iso-concentration surface.

Kikuchi mapping. Transmission Kikuchi diffraction analysis (TKD) was conducted using a Bruker Optimus TKD detector in a Zeiss Merlin field-emission SEM. This system can provide orientation mapping along with phase detection using pre-defined crystal structure inputs of possible phases with a lateral spatia resolution in the order of $10 \mathrm{~nm}$. TKD data were acquired at $30 \mathrm{kV}$ and with $0^{\circ}$ sample tilt. Post-processing of TKD data was conducted using the Bruker-ESPIRIT software.

\section{Auger spectroscopy and X-ray photoelectron spectroscopy. A JAMP} 9500 spectrometer (JEOL, Japan) was used for the AES measurements. Electron beam parameters were $10 \mathrm{keV}$ and $10 \mathrm{nA}$; a spherical electron analyzer was operated in a FRR mode at $0.32 \%$. Concentration quantification was done by taking the peak-to-peak height ratios from differentiated spectra using standard singleelement sensitivity factors. An argon-ion beam operated at $1 \mathrm{keV}$ was used for depth profiling; the sputtering rate equivalent was $3.3 \mathrm{~nm} \mathrm{~min}-1$ for $\mathrm{SiO}_{2}$.

The XPS measurements were carried out at a PHI 5600 CI system (Physical Electronics, USA). Monochromatized Al $K$-alpha X-rays $(350 \mathrm{~W})$ were used and spectra were collected with a hemispherical analyzer operated at $29 \mathrm{eV}$ pass energy. Cleaning by sputtering was done using $\mathrm{Ar}^{+}$ions at $3.5 \mathrm{keV}$.

\section{Data availability}

Source data of the temporal evolution of the XRD patterns presented in Figs. 1, 2, 3, and 4 are available online at (https://archive.materialscloud.org/record/2020.160): https://doi. org/10.24435/materialscloud:nn-38 [ref. ${ }^{61}$ ]. All requests for additional data, for example, raw unprocessed data, background, and geometry calibration files, etc., should be sent to Dr Jiri Orava (j.orava@ifw-dresden.de; jiri.orava@ujep.cz) and Dr Ivan Kaban (i. kaban@ifw-dresden.de).

Received: 13 August 2020; Accepted: 1 April 2021; Published online: 14 May 2021

\section{References}

1. Chen, M. A brief overview of bulk metallic glasses. NPG Asia Mater. 3, 82-90 (2011).

2. Sun, Y., Concustell, A. \& Greer, A. L. Thermomechanical processing of metallic glasses: extending the range of the glassy state. Nat. Rev. Mater. 1, 16039 (2016)

3. Qiao, J. C. Structural heterogeneities and mechanical behavior of amorphous alloys. Prog. Mater. Sci. 104, 250-329 (2019).

4. Ketov, S. V. et al. Rejuvenation of metallic glasses by non-affine thermal strain. Nature 524, 200-203 (2015).

5. Ross, P. et al. Linking macroscopic rejuvenation to nano-elastic fluctuations in a metallic glass. Acta Mater. 138, 111-118 (2017).

6. Pan, J., Ivanov, Yu. P., Zhou, W. H. \& Greer, A. L. Strain-hardening and suppression of shear-banding in rejuvenated bulk metallic glasses. Nature 578, 559-564 (2020).

7. Qiao, J., Jia, H. \& Liaw, P. K. Metallic glass matrix composites. Mater. Sci. Eng. R. 100, 1-69 (2016).

8. Orava, J. et al. Fast-heating-induced formation of metallic-glass/crystal composites with enhanced plasticity. Thermochim. Acta 677, 198-205 (2019).

9. Wang, Y., Chen, M., Zhou, F. \& Ma, E. High tensile ductility in a nanostructured metal. Nature 419, 912-915 (2002).

10. Pauly, S., Gorantla, S., Wang, G., Kühn, U. \& Eckert, J. Transformationmediated ductility in CuZr-based bulk metallic glasses. Nat. Mater. 9, 473-477 (2010).

11. Villapun, V. M., Esat, F., Bull, S., Dover, L. G. \& Gonzalez, S. Tuning the mechanical and antimicrobial performance of a Cu-based metallic glass composite through cooling rate control and annealing. Materials 10, 506 (2017).

12. Cullinan, T. et al. Mechanisms of isothermal devitrification in amorphous $\mathrm{Cu}_{50} \mathrm{Zr}_{50}$. Metall. Mater. Trans. A 46, 600-613 (2015).

13. Kalay, I., Kramer, M. J. \& Napolitano, R. E. High-accuracy X-ray diffraction analysis of phase evolution sequence during devitrification of $\mathrm{Cu}_{50} \mathrm{Zr}_{50}$ metallic glass. Metall. Mater. Trans. A 42, 1144-1153 (2011).

14. Kalay, I., Kramer, M. J. \& Napolitano, R. E. Crystallization kinetics and phase transformation mechanisms in $\mathrm{Cu}_{56} \mathrm{Zr}_{44}$ glassy alloy. Metall. Mater. Trans. A 46, 3356-3363 (2015).

15. Okulov, I. V. et al. Flash Joule heating for ductilization of metallic glasses. Nat. Commun. 6, 7932 (2015).

16. Kosiba, K. et al. Transient nucleation and microstructural design in flashannealed bulk metallic glasses. Acta Mater. 127, 416-425 (2017).
17. Hajlaoui, K. et al. Shear localization and crack blunting of a metallic glass containing nanoparticles: in situ deformation in TEM analysis. Scr. Mater. 54, 1829-1834 (2006)

18. Hajlaoui, K., Alsaleh, N., Alrasheedi, N. H. \& Yavari, A. R. Coalescence and subsequent twinning of nanocrystals during deformation of CuZr-based metallic glasses: the grain size effect. J. Non-Cryst. Solids 464, 39-43 (2017)

19. Küchemann, S. \& Samwer, S. Ultrafast heating of metallic glasses reveals disordering of the amorphous structure. Acta Mater. 104, 119-124 (2016).

20. Küchemann, S. et al. From ultrafast to slow: heating rate dependence of the glass transition temperature in metallic systems. Philos. Mag. Lett. 96, 454-460 (2016).

21. Küchemann, S. et al. Energy storage in metallic glasses via flash annealing Adv. Funct. Mater. 28, 1805385 (2018).

22. Johnson, W. L. et al. Beating crystallization in glass-forming metals by millisecond heating and processing. Science 332, 828-833 (2011).

23. Okulov, I. et al. Fabrication of metastable crystalline nanocomposites by flash annealing of $\mathrm{Cu}_{47.5} \mathrm{Zr}_{47.5} \mathrm{Al}_{5}$ metallic glass using Joule heating. Nanomaterials 10, 84 (2020).

24. Talaat, A., Greve, D. W., Suraj, M. V. \& Ohodnicki, P. R. Jr. Electromagnetic assisted thermal processing of amorphous and nanocrystalline soft magnetic alloys: Fundamentals and advances. J. Alloy. Compd. 854, 156480 (2021).

25. Lee, D. Crystallization behavior upon heating and cooling in $\mathrm{Cu}_{50} \mathrm{Zr}_{50}$ metallic glass thin films. Acta Mater. 121, 68-77 (2016).

26. Miao, Y., Villarreal, R., Talapatra, A., Arróyave, R. \& Vlassak, J. J. Nanocalorimetry and ab initio study of ternary elements in CuZr-based shape memory alloy. Acta Mater. 182, 29-38 (2020).

27. Miao, Y. \& Vlassak, J. J. Explosive martensitic transformation of supercooled austenite in CuZr-based thin-film shape memory alloys. Acta Mater. 200, 162-170 (2020).

28. Cheng, Q. et al. Phase transformations in a $\mathrm{Cu}-\mathrm{Zr}-\mathrm{Al}$ metallic glass. Scr. Mater. 183, 61-65 (2020).

29. Silveyra, J. M., Ferrara, E., Huber, D. L. \& Monson, T. C. Soft magnetic materials for a sustainable and electrified world. Science 362, eaao0195 (2018)

30. Orava, J. et al. Fast-current-heating devices to study in situ phase formation in metallic glasses by using high-energy synchrotron radiation. Rev. Sci. Instrum. 91, 073901 (2020)

31. Gustmann, T. et al. Properties of Cu-based shape-memory alloys prepared by selective laser melting. Shap. Mem. Superelasticity 3, 24-36 (2017)

32. Kosiba, K. Flash-annealing of Cu-Zr-Al-based bulk metallic glasses (Ph.D. Thesis, Technische Universität Dresden, Dresden, Germany, 2017).

33. Wang, D. et al. Bulk metallic glass formation in the binary $\mathrm{Cu}-\mathrm{Zr}$ system. Appl. Phys. Lett. 84, 4029-4031 (2004).

34. Herlach, D. M., Cochrane, R. F., Egry, I., Fecht, H. J. \& Greer, A. L. Containerless processing in the study of metallic melts and their solidification. Int. Mater. Rev. 38, 273-347 (1993).

35. Ivanov, Yu. P., Meylan, C. M., Panagiotopoulos, N. T., Georgarakis, K. \& Greer, A. L. In-situ TEM study of the crystallization sequence in a gold-based metallic glass. Acta Mater. 196, 52-60 (2020).

36. Duan, Y. et al. Crystallization behavior of a confined CuZr metallic liquid film with a sandwich-like structure. Phys. Chem. Chem. Phys. 21, 13738-13745 (2019).

37. Sohn, S., Xie, Y., Jung, Y., Schroers, J. \& Cha, J. Tailoring crystallization phases in metallic glass nanorods via nucleus starvation. Nat. Commun. 8, 1980 (2017).

38. Kissinger, H. E. Reaction kinetics in differential thermal analysis. Anal. Chem. 29, 1702-1706 (1957)

39. Orava, J. \& Greer, A. L. Kissinger method applied to the crystallization of glass-forming liquids: regimes revealed by ultra-fast-heating calorimetry. Thermochim. Acta 603, 63-68 (2015).

40. Kokotin, V., Hermann, H. \& Eckert, J. Computer simulation of the matrixinclusion interphase in bulk metallic glass based nanocomposites. J. Phys. Condens. Matter 23, 425403 (2011).

41. Orava, J. \& Greer, A. L. Fast and slow crystal growth kinetics in glass-forming melts. J. Phys. Chem. 140, 214504 (2014).

42. Wang, Q. et al. Diffusion-controlled crystal growth in deeply undercooled $\mathrm{Zr}_{50} \mathrm{Cu}_{50}$ melt on approaching the glass transition. Phys. Rev. B 83, 014202 (2011).

43. Müller, R., Zanotto, E. D. \& Fokin, V. M. Surface crystallization of silicate glasses: nucleation sites and kinetics. J. Non-Cryst. Solids 274, 208-231 (2000)

44. Lim, K. R. et al. Oxidation resistance of the supercooled liquid in $\mathrm{Cu}_{50} \mathrm{Zr}_{50}$ and $\mathrm{Cu}_{46} \mathrm{Zr}_{46} \mathrm{Al}_{8}$ metallic glasses. J. Mater. Res. 27, 1178-1186 (2012).

45. de Campos Neto, N. D. et al. Phase formation maps in $\mathrm{Zr}_{48} \mathrm{Cu}_{46.5} \mathrm{Al}_{4} \mathrm{Nb}_{1.5}$ bulk metallic glass composites as a function of cooling rate and oxygen concentration. Mater. Charact. 158, 109932 (2019).

46. Zhou, S. H. \& Napolitano, R. E. Identification of the $B 33$ martensite phase in $\mathrm{Cu}-\mathrm{Zr}$ using first-principles and X-ray diffraction. Scr. Mater. 59, 1143-1146 (2008).

47. Zheng, J. et al. Phase transformations in equiatomic CuZr shape memory thin films analyzed by differential nanocalorimetry. Acta Mater. 159, 320-331 (2018). 
48. Sahu, K. K. et al. Phase separation mediate devitrification of $\mathrm{Al}_{88} \mathrm{Y}_{7} \mathrm{Fe}_{5}$ glasses. Acta Mater. 58, 4199-4206 (2010).

49. $\mathrm{Wu}, \mathrm{Y}$. et al. Formation of $\mathrm{Cu}-\mathrm{Zr}-\mathrm{Al}$ bulk metallic glass composites with improved tensile properties. Acta Mater. 59, 2928-2936 (2011)

50. Kargl, F., Weis, H., Unruh, T. \& Meyer, A. Self diffusion in liquid aluminium. J. Phys. Conf. Ser. 340, 012077 (2012).

51. Balachandran, S. et al. Elemental re-distribution inside shear bands revealed by correlative atom-probe tomography and electron microscopy in a deformed metallic glass. Scr. Mater. 168, 14-18 (2019).

52. Boucharat, N., Hebert, R., Rösner, H., Valiev, R. \& Wilde, G. Nanocrystallization of amorphous $\mathrm{Al}_{88} \mathrm{Y}_{7} \mathrm{Fe}_{5}$ alloy induced by plastic deformation. Scr. Mater. 53, 823-828 (2005).

53. Chellali, M. R., Nandam, S. H. \& Hahn, H. Deformation-induced chemical inhomogeneity and short-circuit diffusion in shear bands of a bulk metallic glass. Phys. Rev. Lett. 125, 205501 (2020).

54. Kaban, I. et al. Atomic structure and formation of $\mathrm{CuZrAl}$ bulk metallic glasses and composites. Acta Mater. 100, 369-376 (2015).

55. Guo, W., Saida, J., Zhao, M., Lü, S. \& Wu, S. Non-thermal crystallization process in heterogeneous metallic glass upon deep cryogenic cycling treatment. J. Mater. Sci. 54, 8778-8785 (2019).

56. Hammersley, A. P. et al. Calibration and correction of distortions in two dimensional detector systems. Rev. Sci. Instrum. 66, 2729-2733 (1995).

57. Hammersley, A. P., Svensson, S. O., Hanfland, M., Fitch, A. N. \& Häusermann, D. Two-dimensional detector software: from real detector to idealised image or two-theta scan. High. Press. Res. 14, 235-248 (1996).

58. Hammersley, A. P. ESRF Internal Report, ESRF98HA01T, FIT2D V9.129 Reference Manual V3.1, (1998).

59. Degen, T., Sadki, M., Bron, E., König, U. \& Nénert, G. The HighScore suite. Powder Diffr. 29, S13-S18 (2014).

60. Shuleshova, O. et al. Metastable phase formation in undercooled Fe-Co melts under terrestrial and microgravity conditions. IFW Dresd.: Annu. Rep. 2017, 39-42 (2018)

61. Orava, J. et al. In situ high-energy X-ray diffraction of a CuZr-based metallic glass. Mater. Cloud Arch. 2020, 160 (2020).

\section{Acknowledgements}

J.O., S.B., M.H., and I.K. are grateful to the Deutsche Forschungsgemeinschaft (DFG), contracts No.: Ka-3209/9-1 and HE 7225/1-1, for funding. Y.P.I. and A.L.G. acknowledge support from the European Research Council under the European Union's Horizon 2020 research and innovation program (grant ERC-2015-AdG-695487: Extend Glass). We acknowledge DESY (Hamburg, Germany), a member of the Helmholtz Association HGF, for the provision of experimental facilities. Parts of this research were carried out at the beamline P21.1 at PETRA III. We are grateful to S. Donath, S. Kaschube, B. Opitz, H. Siegel and S. Ziller (IFW Dresden) for technical support.

\section{Author contributions}

J.O. and I.K. led the project and wrote the manuscript with input from all the authors. X.H. synthesized master alloys and prepared ribbons. J.O., X.H., I.S., and I.K. constructed the flash-annealing device. I.S. developed software for controlled heating. I.S. and O.G. implemented and synchronized flash-annealing with beamline and detector. J.O., X.H., and I.K. did synchrotron measurements of flash-annealing. J.O., X.H., and O.S. analyzed high-energy X-ray diffraction data. J.O., X.H., O.S., and I.K. performed and analyzed containerless experiments. O.G., O.I., A.C.D., and Mv.Z. were responsible for running the synchrotron facility. S.B., E.N., D.R., and M.H. did the atom probe tomography measurements and data interpretation together with J.O. Y.P.I., and A.L.G. carried out TEM measurements and data interpretation. S.O. measured and analyzed Auger and XPS spectra. I.K. and M.H. obtained the funding to support the study. All authors contributed to the interpretation and presentation of the results.

\section{Funding}

Open Access funding enabled and organized by Projekt DEAL.

\section{Competing interests}

The authors declare no competing interests.

\section{Additional information}

Supplementary information The online version contains supplementary material available at https://doi.org/10.1038/s41467-021-23028-9.

Correspondence and requests for materials should be addressed to J.O., S.B., X.H. or I.K.

Peer review information Nature Communications thanks Marios Demetriou, Si Lan and Howard Sheng for their contribution to the peer review of this work.

Reprints and permission information is available at http://www.nature.com/reprints

Publisher's note Springer Nature remains neutral with regard to jurisdictional claims in published maps and institutional affiliations.

(c) (i) Open Access This article is licensed under a Creative Common Attribution 4.0 International License, which permits use, sharing adaptation, distribution and reproduction in any medium or format, as long as you give appropriate credit to the original author(s) and the source, provide a link to the Creative Commons license, and indicate if changes were made. The images or other third party material in this article are included in the article's Creative Commons license, unless indicated otherwise in a credit line to the material. If material is not included in the article's Creative Commons license and your intended use is not permitted by statutory regulation or exceeds the permitted use, you will need to obtain permission directly from the copyright holder. To view a copy of this license, visit http://creativecommons.org/ licenses/by/4.0/.

(c) The Author(s) 2021 